\title{
DESIGUALDADES COMPLEJAS Y ENTRELAZADAS: UNA PROPUESTA DE TRATAMIENTO JURÍDICO-POLÍTICO*
}

\author{
COMPLEX AND INTERTWINED INEQUALITIES: \\ A PROPOSAL FOR A LEGAL-POLITICAL TREATMENT
}

RAÚL SUSÍN BETRÁN

Universidad de La Rioja

Fecha de recepción: 14-12-19

Fecha de aceptación: 12-5-20

Resumen: Este trabajo defiende que la pluralidad y diversidad de nuestras sociedades hace necesario pensar formas complejas de tratamiento jurídico-político de la desigualdad. En este sentido, a partir del comentario de una actuación normativa vinculada con el velo islámico integral, que al no compartir lo anterior provoca efectos negativos, este trabajo propone una concepción de la justicia que integre redistribución y reconocimiento, al tiempo que se reivindica la importancia del diálogo y la incorporación de nuevas perspectivas como la interseccionalidad.

Abstract: This paper argues that the plurality and diversity of our societies makes it necessary to think about complex forms of legal-political treatment of inequality. In this sense, based on the commentary of a normative action linked to the full-face Islamic veil that, by not sharing the above, causes negative effects, this work proposes a conception of justice that integrates redistribution and recognition, while claiming the importance of dialogue and the incorporation of new perspectives such as intersectionality.

Palabras clave: desigualdad, reconocimiento y redistribución, velo islámico integral, diálogo, interseccionalidad

Key words: $\quad$ inequality, recognition and redistribution, full-face Islamic veil, dialogue, intersectionality

* $\quad$ Este trabajo se ha realizado en el marco del proyecto DER2017-82173-R ("El impacto de la globalización en las fuentes del derecho y su repercusión en los principios de seguridad y legitimidad jurídica").

ISSN: 1133-0937

DERECHOS Y LIBERTADES

DOI: https://doi.org/10.20318/dyl.2021.5849

Número 44, Época II, enero 2021, pp. 41-79 


\section{DESIGUALDADES COMPLEJAS Y ENTRELAZADAS}

Diseñar una política y un tratamiento jurídico-político que tienda a la igualdad exige pensar en la desigualdad, de la cual, para lo que ahora nos interesa, conviene saber que está condicionada por el hecho de que nos encontramos en unas sociedades que hace ya unas décadas han dejado de ser uniformes y homogéneas. De esta forma, el trabajo con la desigualdad en sociedades plurales que se pretendan democráticas debe afrontarse con una perspectiva compleja e interdependiente que puede tomar múltiples formas con múltiples consecuencias ${ }^{1}$.

Sin embargo, también conviene advertir que la pluralidad señalada no puede hacernos olvidar la importancia de actuaciones políticas y desarrollos normativos orientados a corregir las situaciones de desigualdad de recursos y de desigualdad material. Esto es, no puede hacernos dejar de lado la importancia de la igualdad de recursos para desenvolvernos; ni que la calidad de las relaciones sociales se construye sobre cimientos materiales; ni tampoco que cuando las diferencias de renta son mayores las distancias sociales se agrandan y la estratificación social cobra una mayor importancia. En relación con esto último -y aludiendo a la conocida imagen del "ascensor social"-: cuando el ascensor social se para, ir por las escaleras tiene efectos dañinos para la salud, las expectativas de vida y los valores básicos humanos. Dicho de otra forma, las personas que no pueden controlar lo más básico de su existencia por falta de recursos, tampoco pueden controlar la salud de sus cuerpos, ni sus oportunidades como organismos en mundos hostiles, ni pueden acceder a ser personas más felices o más sanas... Por eso, sería un ejercicio de cinismo no reconocer la necesidad de políticas que corrijan esas desigualdades materiales y de recursos como pilar ineludible para subsanar asimetrías y mejorar las oportunidades y, con ellas, la calidad de vida de cada uno de nosotros mismos y de nuestro entorno social, a la vez que para avanzar hacia una sociedad más justa y democrática.

Con todo, si lo anterior es cierto y exige actuar en el plano de la redistribución justa, también es cierto que hoy deberíamos tener en cuenta que

1 Para afrontar la perspectiva compleja e interdependiente que se propone, resulta de interés la "inmersión rápida" en la igualdad, con referencias a la justicia como reconocimiento, redistribución y representación-inclusión, a la concepción de la igualdad como relación y, entre otras, al debate sobre la igualdad, la identidad y la diferencia en las sociedades multiculturales, de O. PÉREZ DE LA FUENTE, Igualdad. Una inmersión rápida, Tibidabo ediciones, Barcelona, 2017. 
trabajar únicamente la desigualdad material y de recursos no va a ser suficiente y que se trata de pensar actuaciones jurídico-políticas que, en cierta medida, vayan más allá de la igualdad ${ }^{2}$, por lo menos de lo que hasta hace no mucho entendíamos como una exigencia unidimensional de igualdad. Así, resulta obligado ampliar el concepto de igualdad, tal y como distintos movimientos sociales y políticos (género, identidad, raza...) han ido poniendo de manifiesto con sus denuncias en las últimas décadas del siglo pasado y en lo que llevamos del XXI y, en este sentido, podemos servirnos del trabajo de Goran Therborn, quien al inicio de La desigualdad mata dice: "La desigualdad es una violación de la dignidad humana, una negación de la posibilidad de desarrollo de las capacidades humanas"; y continúa: "Puede adoptar múltiples formas y tiene múltiples consecuencias: muerte prematura, mala salud, humillación, subyugación, discriminación, pobreza, impotencia, estrés, inseguridad, ansiedad, falta de confianza en uno mismo y de amor propio y exclusión de oportunidades que ofrece la vida. La desigualdad, por tanto, no se relaciona exclusivamente con el tamaño de la billetera. Es un orden sociocultural que reduce nuestra capacidad para funcionar como seres humanos, nuestra salud, la autoestima, nuestra percepción del propio yo, así como nuestros recursos para actuar y participar en el mundo" 3 .

Nos referimos, de este modo, a una desigualdad compleja que conforma todo un "orden sociocultural" caracterizado por la ausencia de la igualdad necesaria para existir; esto es, por la imposibilidad de "poder optar por una vida de dignidad y bienestar" de acuerdo con lo que requieren las dimensiones básicas de la vida humana en tanto que organismos, actores y personas. De lo que, siguiendo a Therborn, se derivarían tres tipos de desigualdad: vital (la vinculada con la salud y la esperanza de vida), de recursos (la que se vincula con la desigualdad de recursos para desenvolverse, entre ellos como básico el monetario) y existencial (la que se relaciona con "la desigualdad personal de autonomía, dignidad, grados de libertad y de derecho al respeto y al desarrollo personal" $)^{4}$.

2 Esta expresión, "la igualdad más allá de la igualdad", es prácticamente un lugar común, pero en este caso la recojo de un trabajo sobre el que luego volveremos: L. VILLAVICENCIO MIRANDA, "Justicia social y el principio de igualdad", Hybris. Revista de Filosofía, vol. 9, núm. especial: Debates contemporáneos sobre Justicia Social, julio-2018, pp. 43-74.

3 G. THERBORN, La desigualdad mata, trad. F. Muñoz de Bustillo, Alianza editorial, Madrid, 2015, p. 11.

$4 \quad$ Ibidem, pp. 57-58.

ISSN: 1133-0937

DERECHOS Y LIBERTADES

DOI: https://doi.org/10.20318/dyl.2021.5849

Número 44, Época II, enero 2021, pp. 41-79 
Así, siendo importantes la desigualdad vital y la de recursos que nos remiten a injusticias más de orden socioeconómico y entendiendo, además, que estos tres tipos de desigualdad interactúan y son interdependientes, conformando una especie de círculo vicioso de subordinación, la introducción de la desigualdad existencial nos lleva a considerar un nivel de injusticia cultural o simbólica en la que en la pluralidad de nuestras sociedades merece la pena invertir algún tiempo. Pero conviene, en cualquier caso, tener presente de manera constante lo enredado de las desigualdades e injusticias y, de esta forma, como se irá viendo a lo largo del trabajo en distintas referencias, resulta sugerente la concepción de Nancy Fraser, quien ha sostenido el entrecruzamiento de la injusticia económica y cultural y el refuerzo de una con otra hasta el punto de acabar en el citado "círculo vicioso de subordinación cultural y económica"; advirtiendo que de ninguna manera puede resultar aceptable que el reconocimiento sea la excusa para desplazar a la redistribución en las luchas frente a la injusticia, y esto ni en momentos de incremento de las desigualdades por los efectos del neoliberalismo ${ }^{5}$, ni cuando el populismo reaccionario ha superado a un "neoliberalismo progresista" que igualmente ha sacrificado la protección social y el bienestar material por "un falso concepto de emancipación en términos de meritocracia, diversidad y empoderamiento" 6 .

Como también -sobre este entrecruzamiento- recoge Fraser en otro trabajo, Justice Interruptus, donde recurre al concepto de "esfera pública" y a Habermas para, entre otras cosas, realizar una crítica de una democracia liberal que entiende que la eliminación de la desigualdad social no es una

$5 \quad$ N. FRASER, “ ¿De la redistribución al reconocimiento? Dilemas de la justicia en la era 'postsocialista'”, en Ma . A. CARBONERO GAMUNDÍ y J. VALDIVIESO (eds.), Dilemas de la Justicia en el siglo XXI. Género y globalización, trad. M. W. Jones y J. Valdivieso, Edicions UIB, Palma-Illes Balears, 2011, pp. 217-254 (reedición en castellano de un artículo publicado en New Left Review, 212, 1995, pp. 68-93), donde también se puede leer la declaración de intenciones de la autora en lo que significa para ella la teoría del reconocimiento, algo que compartimos en este trabajo: "En vez de, simplemente, sumarse a o rechazar toda la política de identidad simpliciter, tendríamos que considerar que se nos ha presentado una nueva tarea intelectual y práctica: la de desarrollar una teoría crítica del reconocimiento, una que identifique y defienda solo aquellas versiones de la política cultural de la diferencia que puedan combinarse coherentemente con la política social de la igualdad".

6 Este "desplazamiento" de la redistribución por el reconocimiento lo vincula Fraser con un "neoliberalismo progresista" que relaciona, a su vez, con la candidatura demócrata a la que derrotó electoralmente Trump en 2016; N. FRASER, “Saltar de la sartén para caer en las brasas. Neoliberalismo progresista, frente a populismo reaccionario", trad. C. Conde, en VV. AA., El gran retroceso, Seix Barral, Barcelona, 2017, pp. 95-108. 
condición necesaria de la democracia política y que es suficiente con ponerla en suspenso: "La economía política refuerza estructuralmente lo que la cultura consigue informalmente"; y vinculando su reflexión con la participación y la democracia: "Es condición necesaria de la paridad de participación que las desigualdades sociales sistemáticas sean eliminadas. Esto no significa que todo el mundo deba tener exactamente la misma renta, pero sí requiere el tipo de igualdad aproximada que es incompatible con las relaciones de dominación y subordinación generadas de forma sistémica. Pese al liberalismo, entonces, la democracia política requiere una igualdad social sustantiva" 7 .

Y desde otra perspectiva que también guarda una cierta relación y refuerza lo dicho en el párrafo anterior, debemos tener en cuenta que las relaciones sociales no dejan de construirse sobre cimientos materiales; esto es, como correctamente sostienen Wilkinson y Pickett con un contundente apoyo en datos empíricos: "La reducción de la desigualdad puede ser un potente nivelador de nuestro bienestar". Reduciendo la desigualdad económica se aminoran los problemas sociales y de salud, los problemas de (in)-movilidad social, violencia y corrosión social... lo que lleva a menos muros, menos prejuicios, más confianza, más reconocimiento del otro..., y, como concluyen su investigación estos autores, lleva a "una sociedad cualitativamente mejor y, valga la tautología, más 'sociable'" 8 .

Volviendo a la desigualdad existencial, como apuntábamos siguiendo a Therborn, está vinculada "con atribuciones desiguales de la autonomía personal, el reconocimiento y el respeto, con negaciones de la igualdad existencial de los seres humanos, a quienes se impide desarrollar plenamente su capacidad de funcionamiento" ${ }^{\prime 2}$. Es una desigualdad que se alimenta de la confluencia de distintos vectores: patriarcado y misoginia, sexismo, racismo y xenofobia, islamofobia, antisemitismo, colonialismo,

N. FRASER, "Repensar la esfera pública. Una contribución a la crítica de la democracia actualmente existente", en $\mathrm{M}^{\mathrm{a}}$. A. CARBONERO GAMUNDÍ y J. VALDIVIESO (eds.), Dilemas de la Justicia en el siglo XXI. Género y globalización, cit., pp. 151-156 (es una reedición en castellano de un capítulo de Justice Interruptus. Critical reflections on the 'postsocialist' conditions, obra que Fraser publica inicialmente en 1997).

8 R. WILKINSON y K. PICKETT, Desigualdad. Un análisis de la (in)felicidad colectiva, trad. Laura Vidal, Turner Publicaciones, Madrid, 2009; y también, de los mismos autores, profundizando en estas cuestiones y, en sentido contrario, apuntando a la igualdad como clave para mejorar el bienestar colectivo y construir una sociedad mejor, Id., Igualdad, trad. C. Martínez, Capitán Swing, Madrid, 2019.

9 G. THERBORN, La desigualdad mata, cit., p. 59. 
heteronormatividad, explotación de poblaciones dominadas por poblaciones dominantes, empobrecimiento de la clase trabajadora (y, con ello, criminalización del pobre económico como pobre moral $)^{10}$. Desde esta confluencia podemos reconocer el (des)-valor de la diferencia como estrategia de exclusión y subordinación y, al mismo tiempo, adelantar las posibilidades que pueda tener la herramienta conceptual de la interseccionalidad, sobre la que luego volveremos, sin tampoco dejar de lado la vinculación de estas cuestiones con un cierto feminismo del que es un buen exponente el discurso de Angela Davis en la Marcha de las mujeres en Washington ${ }^{11}$. Es esta, la existencial, una desigualdad que tiene que ver con cómo cada persona vive su vida en contextos sociales llenos de significados y emociones y que, entre sus consecuencias más negativas, tiene efectos sobre nuestra autoestima; sobre cómo consideramos y tratamos a los demás y cómo actuamos y participamos en el mundo; sobre la calidad de nuestras relaciones sociales y los niveles de desmembración social y de erosión de la cohesión social; sobre la desconfianza que nos transmite el otro.... En definitiva, efectos que van más allá de las cuestiones y estructuras económicas o de poder del Estado y que se refieren a nuestras vidas cotidianas y a nuestra vida cohabitando en sociedad con otros.

10 En el citado trabajo de Therborn se puede leer en relación a esta desigualdad existencial y a la confluencia de estas "tendencias" como generadoras de desigualdad: "Desde 1945 se ha producido una tendencia generalizada hacia la igualdad existencial y el mundo actual se sigue moviendo hacia la igualdad de autonomía personal, el reconocimiento y el respeto de todas las personas", si bien esto no es algo generalizado a nivel global y todavía encontramos zonas donde siguen vivos, y "gobernando", el sexismo, la xenofobia, el antisemitismo, la islamofobia, el antiarabismo, el patriarcado y la misoginia; matizando más adelante: "No obstante, aunque la desigualdad existencial patente e institucionalizada, que actuaba en forma de racismo, xenofobia, sexismo y desarrollismo despiadado (...), haya sido erosionada, la desigualdad existencial aún forma parte integral de las sociedades contemporáneas"; y añadiendo, finalmente: "Actualmente también existen tendencias sociales que producen nuevas formas de desigualdad existencial: la desindustrialización motivada por la deslocalización, la inmigración de los pobres y la marginación que provoca el mercado laboral"; Ibidem, pp. 91-96.

11 En enero de 2017 esa Marcha concluye con un acto en Washington donde en el discurso que pronuncia Angela Davis podemos leer: "Esta es una marcha de mujeres que representa la promesa del feminismo en contra de los poderes perniciosos de la violencia estatal. Un feminismo inclusivo e interseccional que invita a todos a unirnos a la resistencia al racismo, a la islamofobia, al antisemitismo, a la misoginia y a la explotación capitalista" (entre otros lugares, accesible la versión en castellano del discurso, última consulta diciembre de 2019, en: http://www.rebelion.org/noticia.php?id=222454). 


\section{LA COMPLEJIDAD DE UN CASO REAL. ALGUNOS DÉFICITS DE SU TRATAMIENTO NORMATIVO}

Un caso real nos puede ayudar a comprender la conveniencia de pensar principios y actuaciones normativas acordes con la complejidad de las sociedades plurales, que es lo que se está intentando plantear en esta aportación incidiendo en esta desigualdad existencial que, en acción -recogiendo una idea de Barrère- se convierte en discriminación ${ }^{12}$; esto es, nos puede ayudar a ver que las actuaciones políticas y normativas deben tener en cuenta esa complejidad si no quieren acabar teniendo efectos distintos, e incluso opuestos, a los objetivos declarados.

El caso en cuestión tiene que ver con la ley francesa 2010-1192 que prohíbe el ocultamiento del rosto en lugares públicos, aprobada el 11 de octubre de 2010 y que entró en vigor seis meses después, el 11 de abril de 2011. Esta norma fue impulsada por el Gobierno Sarkozy en un contexto de politización y radicalización del debate público entre los polos de la pertenencia cultural-religiosa y los principios republicanos -sin olvidar el condicionante de la creciente obsesión securitaria- y, cuando menos, pone en cuestión la capacidad del legislador para responder a la creciente pluralidad de la sociedad con una correcta articulación de universalismo y multiculturalismo ${ }^{13}$. Así, aunque en su escueto articulado no se encuentra referencia alguna al velo integral, lo que le podría aportar una falsa apariencia de neutralidad, sí que lo hace la norma que desarrolla su aplicación, donde encontramos referencia directa a los velos integrales islámicos (burqa y niqab), con lo que podríamos considerar que indirectamente también a sus portadoras: mujeres que profesan la fe islámica; y donde se viene a recoger que ocultar el rostro socava

12 En su defensa de la necesaria coherencia entre las políticas de igualdad y el derecho antidiscriminatorio, dice Barrère: "La razón estriba en que la discriminación (se manifieste estructural o individualizadamente, se reconozca o no jurídicamente y se sancione positiva o negativamente) no es más que la desigualdad en acción"; Ma . Á., BARRÈRE, "La interseccionalidad como desafío al mainstreaming de género en las políticas públicas", Revista Vasca de Administración Pública, núm. 87-88, 2010, p. 228.

13 En este sentido, una contextualización crítica de este proceso legislativo y de las practicas administrativas vinculadas, incidiendo en la radicalización de las posiciones al iniciar el siglo XXI que explicaría el tránsito desde la ley 2004-228, que regulaba el uso de símbolos religiosos en centros educativos, a esta 2010-1192, que interviene en el control de todo el espacio público, lo encontramos en: V. CHAMPEIL-DESPLATS, “Laïcité et liberté religieuse en France: aux sources de la loi interdisant la dissimulation intégrale du visage dans l'espace public", Revista Derecho del Estado, núm. 29, 2012, pp. 51-72 (sobre todo, 62-72). 
las exigencias mínimas de la vida en sociedad y coloca a las personas en una situación de exclusión e inferioridad incompatible con los principios de libertad, igualdad y dignidad humana ${ }^{14}$. De cualquier manera, debemos tener en cuenta que no nos estamos pronunciando sobre el significado de portar el velo integral y sobre si detrás de este signo subyace una cultura de dominación de un sexo sobre otro, sino que, insisto, nos ocupa este caso para atender a los efectos que tal intervención político-normativa puede tener ${ }^{15}$.

Así, podemos recoger lo que ocurrió con Kenza Drider, ciudadana francesa residente en Avignon y que, como portadora de un tipo de velo integral, el niqab, participó en los trabajos parlamentarios previos a la elaboración de la ley ${ }^{16}$. De acuerdo a lo allí recogido, para Kenza Drider su dignidad y su libertad, su desarrollo personal en orden a vivir fiel a sus creencias religiosas consistía, precisamente, en poder llevar a cabo la decisión de portar el niqab. Lo que le llevó a anunciar antes de la entrada en vigor de la norma que si bien no se negaría a ser identificada cuando se le requiriese -de hecho en

14. Loi $n^{\circ}$ 2010-1192 du 11 octobre 2010 interdisant la dissimulation du visage dans l'espace public. En su artículo 1, esta norma recoge: "Nadie puede, en el espacio público, llevar una vestimenta destinada a ocultar su rostro"; estableciéndose, conjuntamente con la normativa sancionadora, que las infracciones de este precepto pueden acarrear multas de hasta 150 euros y/o la obligación de realizar cursos de ciudadanía. Además, y en esto creo que el debate es lógicamente distinto, también se recogen otras sanciones económicas más severas (30.000 euros) y penas de privación de libertad para quienes impongan llevar esa prenda a través de amenaza, violencia, coacción, abuso de autoridad o poder, endureciéndose el castigo si la víctima es una persona menor de edad. Y Circulaire du 2 mars 2011 relative à la mise en oeuvre de la Loi $n^{\circ}$ 2010-1192 du 11 octobre 2010 interdisant la dissimulation du visage dans l'espace public.

15 Esta es la línea seguida en octubre de 2018 por el Comité de Derechos Humanos de Naciones Unidas al resolver contra Francia sobre dos denuncias de dos mujeres sancionadas por llevar velo integral. Así, en la noticia recogida en la web del Alto Comisionado de Naciones Unidas, el presidente del Comité, Yuval Shany, manifestaba: “Estas decisiones no menoscaban el principio de laicidad y no tienen por objeto promover una costumbre, que muchos en el Comité, incluido yo mismo, consideramos una forma de opresión contra la mujer"; explicando, seguidamente, que la decisión del Comité pone en evidencia que una prohibición generalizada con carácter sancionador, como la contenida en la norma francesa, resulta demasiado amplia y no permite asegurar un equilibrio razonable entre interés general y libertades individuales (www.ohchr.org/FR/NewsEvents/Pages/DisplayNews.aspx?NewsID=23750ELangI$D=F$, última consulta en diciembre de 2019 y donde se puede acceder a los dictámenes íntegros en distintos idiomas).

16 Véase el informe de la Mission d'information sur la pratique du port du voile intégral sur le territoire national: Rapport d'information no 2262, Assenblée National, 26 janvier 2010 (última consulta en diciembre de 2019 en: http://www.assemblee-nationale.fr/13/rap-info/i2262. asp\#P551_92327).

DERECHOS Y LIBERTADES

ISSN: 1133-0937

Número 44, Época II, enero 2021, pp. 41-79

DOI: https://doi.org/10.20318/dyl.2021.5849 
su comparecencia parlamentaria se retiró el velo y así lo hacía también en otras ocasiones delante de hombres, como cuando acudía a reuniones con los profesores de sus hijos o tenía que verificar su identidad en un control de seguridad ${ }^{17}$-, la existencia de la norma, su prohibición y sus sanciones, no conseguirían que dejara de portar el niqab en el espacio público. Se trataba, además, de una decisión en la que no había presiones familiares, pues ella era pionera en su familia en portar la prenda, algo que -el ser pioneras en el entorno familiar-, por otro lado, parece que no es extraño a otros casos y creo que es relevante a la hora de evaluar el significado de las actuaciones político-normativas que prohíben y sancionan el uso del velo ${ }^{18}$. Finalmente, el mismo día en que entró en vigor la norma Kenza Drider fue detenida en Paris, junto a la catedral de Notre Dame, con un grupo de mujeres que portaban el velo integral, pero no por esa razón, sino por llevar a cabo una concentración sin autorización.

Más allá del caso en sí de Kenza Drider, su realidad nos sirve para hacer una lectura del significado de la norma. Quizás lo primero a recoger sea que es una norma que ha tenido una vida legislativa un tanto controvertida; algo acorde, por otra parte, con lo poco pacífica que se presenta la cuestión de la utilización de vestimentas religiosas y otros símbolos de pertenencia

17 Rapport d'information $n^{\circ}$ 2262, Assemblée nationale, 26 janvier 2010.

18 En este sentido, si bien no es fácil encontrar estudios que den voz a las mujeres portadoras del velo integral, existe uno publicado por la Open Society Foundations en abril de 2011 donde se recogen 32 entrevistas a mujeres que lo llevaban, siendo, en su mayoría, las primeras de su familia en portarlo. En la conclusión del informe se recoge que estas mujeres afirmaban que su decisión era libre, sin otra influencia que sus propias lecturas, incluso con la oposición de sus familias. En estas conclusiones también se relata que desde el inicio del debate en Francia sobre la iniciativa legislativa prohibicionista había aumentado la agresión verbal contra las mujeres portadoras de velo integral, lo cual pone en cuestión que se cumpla el objetivo de la ley de avanzar en la causa de la dignidad de las mujeres. Este informe, "Un voile sur les Réalités. 32 musulmanes de France expliquent pourquoi elles portent le voile intégral", puede consultarse íntegramente en sus versiones en inglés y francés en: www.opensocietyfoundations. org/publications (última consulta en junio de 2019). Otra investigación con resultados similares fue la realizada con 27 mujeres portadoras de velo integral por el Human Rights Centre of Ghent University y que encontramos publicada en E. BREMS, Y. JANSSENS, K. LECOYER, S. OUALD CHAIB, V. VANDERSTEEN y J. VRIELINK, “The Belgian 'burqa ban' confronted with insider realities", en E. BREMS (ed.), The experiences of face veil wearers in Europe and the law, Cambridge University Press, Cambridge, 2014, pp. 77-114. Finalmente, en esa misma publicación colectiva también encontramos en la Parte I otros capítulos donde se recogen investigaciones empíricas realizadas en Dinamarca, Holanda y Reino Unido sobre la experiencia de mujeres que llevan velo integral.

ISSN: 1133-0937

DERECHOS Y LIBERTADES

DOI: https://doi.org/10.20318/dyl.2021.5849

Número 44, Época II, enero 2021, pp. 41-79 
en el espacio público, y esto al margen de si al final reconocemos que hay o no conflicto entre valores y derechos o el tema es más bien de límites de los mismos ${ }^{19}$. Así, por ejemplo, de una parte, en octubre de 2010 el Consejo Constitucional francés avaló en un dictamen vinculante la constitucionalidad de la prohibición, con la salvedad de que la consideraba inaplicable en los lugares de culto abiertos al público. Sin embargo, de otra parte, el Consejo de Estado, unos meses antes, marzo de 2010, había planteado la conveniencia de sustituir esta propuesta regulativa por otra que evitase sanciones negativas y que no estableciese una prohibición general para todos los lugares públicos, sino solo para aquellos en los que la seguridad o el riesgo de fraude aconsejasen la limitación en su uso ${ }^{20}$.

Tampoco ha sido pacífica la vida de la norma una vez que ha entrado en vigor y prueba de ello es, por ejemplo, que, de un lado, el Tribunal Europeo de Derechos Humanos (TEDH) dictaminó en el asunto S.A.S contra Francia, julio de 2014, que la norma -y su prohibición general- resultaba acorde con el contenido de los derechos recogidos en el Convenio Europeo de Derechos Humanos (CEDH) (arts. 8, 9 y 10, individualmente o en rela-

19 Resulta de interés acudir a Á. SOLANES, Derechos y culturas. Los retos de la diversidad en el espacio público y privado, Tirant lo Blanch, Valencia, 2018, sobre todo, pp. 150-203, donde, con referencias a casos concretos, a distintas resoluciones judiciales y a tratamientos normativos, entre ellos -pero no solo- este de la norma francesa, se analiza la cuestión del velo integral; la presencia de símbolos religiosos estáticos en el espacio público; y, finalmente, el uso de la vía pública para actividades religiosas y culturales. Por otra parte, sobre la cuestión de si existe conflicto de valores y derechos o es un tema de límites de los mismos, volveremos más adelante -al hilo de los efectos de riesgo de desubjetivización de la norma prohibicionista- con referencias a M. MALIK, "El derecho de la igualdad: resolviendo conflictos de igualdad y derechos humanos. La experiencia británica”, Anales de la Cátedra Francisco Suárez, núm. 45, 2011, pp. 109-146.

20 Véase, con respecto al Consejo Constitucional, la Décision n $n^{0}$ 2010-613 DC du 07 octobre 2010 (última consulta en diciembre de 2019 a través de la web del Consejo Constitucional francés: www.conseil-constitutionnel.fr); mientras que con respecto al Consejo de Estado habría que consultar el Informe adoptado por su Asamblea General Plenaria con fecha de 25 de marzo de 2010, “Étude relative aux possibilités juridiques d'interdiction du port du voile integral" (última consulta en diciembre de 2019 a través de la web del Consejo de Estado francés: www.conseil-etat.fr). También podríamos recoger aquí la línea seguida por la Asamblea Parlamentaria del Consejo de Europa en su Resolución 1743 (2010), "Islam, islamisme e islamophobie en Europe", donde si bien se reconoce que esta tradición de llevar burqa o niqab puede representar una amenaza para la libertad y dignidad de las mujeres, también se desaconseja una prohibición total y general del uso de los velos integrales, salvo determinadas circunstancias, como, por ejemplo, por motivos de seguridad (accesible, última consulta diciembre 2019, a través de la web de la Asamblea Parlamentaria del Consejo de Europa: www.assembly.coe.int).

DERECHOS Y LIBERTADES

ISSN: 1133-0937

Número 44, Época II, enero 2021, pp. 41-79

DOI: https://doi.org/10.20318/dyl.2021.5849 
ción al 14) ${ }^{21}$; jurisprudencia que se consolidó posteriormente con, por ejemplo, otras resoluciones de 2017 vinculadas con prohibiciones similares establecidas en Bélgica ${ }^{22}$. Mientras que, de otro lado, el Comité de Derechos Humanos de Naciones Unidas, encargado de velar por el cumplimiento del Pacto Internacional de Derechos Civiles y Políticos, dictaminó, en octubre de 2018 y a partir de dos denuncias de dos mujeres que habían sido sancionadas en 2012 por llevar velo integral en espacios públicos, que la norma establecía una prohibición excesivamente general y amplia y que podía tener el efecto contrario al pretendido, esto es, podía acabar dificultando los procesos de integración social ${ }^{23}$.

21 Sentencia del TEDH (Gran Sala) en el asunto S.A.S contra Francia, no 43835/11, de 1 de julio de 2014. Un análisis crítico de esta resolución, fijándose, sobre todo, en el argumento del "vivre ensemble" y en el reconocimiento al Estado francés de un amplio "margen de apreciación" que le permite una lectura restrictiva de derechos y libertades a través de la norma que prohíbe el uso del velo integral en espacios públicos, lo encontramos en: V. CAMARERO y F. J. ZAMORA, "La sentencia del TEDH en el caso S.A.S. c. Francia: un análisis crítico”, Revista General de Derecho Canónico y Derecho Eclesiástico del Estado, núm. 37, 2015. También conviene recoger aquí la crítica que a las restricciones a las libertades en este tema en base al concepto jurídico indeterminado de "convivencia" hace Á. SOLANES, "Límites a los derechos en el espacio público: mujeres, velos y convivencia", Cuadernos Electrónicos de Filosofía del Derecho, núm. 31, 2015, pp. 62-91. Finalmente, S. OUALD CHAIB and L. PERONI, “S.A.S. v. France: Missed opportunity to do full justice to women wearing a face veil", july 3, 2014 (accesible, mayo 2020, en: strasbourgobservers.com/2014/07/03/) coincide en críticar el argumento del "vivre ensemble", pero recoge elementos positivos de la sentencia, como la incorporación en la Corte del lenguaje de igualdad de género y, en relación con ello, que se abandone la consideración de las mujeres musulmanas como oprimidas, además de la integración de algunos aspectos procesales.

22 STEDH (Sección Segunda) en el asunto Belcacemi y Oussar contra Bélgica, nº 37798/13, de 11 de julio de 2017; y STEDH (Sección Segunda) en el asunto Dakir contra Bélgica, n 4619/12, de 11 de julio de 2017. Un comentario crítico de ambas resoluciones -compartiendo también la vaguedad del "vivre ensemble" apuntada en la nota anterior y, recogiendo, entre otras cosas, que no se presta atención al impacto de la prohibición sobre las mujeres y que es la mayoría quien dicta las condiciones de convivencia e interacción social que limitan el pluralismo religioso- lo encontramos en: M. FERRI, “Belkacemi and Oussar v Belgium and Dakir v Belgium: the Court again addresses the full-face veil, but it does not move away from its restrictive approach", july 25, 2017 (accesible, mayo de 2020, en: strasbourgobservers.com/2017/07/25/). Sin embargo, también cabe recoger que la STEH (Sección Segunda) en el asunto Lachiri contra Bélgica, n 3413/09, de 18 de septiembre de 2018, resolvió que había habido una violación del art. 9 del CEDH cuando a la solicitante no se le permitió el acceso a la sala de un tribunal por portar un hiyab, aunque el TEDH señala en su resolución la diferencia entre el "foulard islamique" y lo que en el caso de S.A.S. contra Francia era "una prenda que oculta todo el rostro con la excepción eventual de los ojos".

23 Dictamen aprobado por el Comité a tenor del artículo 5, párrafo 4, del Protocolo Facultativo, respecto de la comunicación núm. 2747/2016; y Dictamen aprobado por el Comité a tenor del artículo 5,

ISSN: 1133-0937

DERECHOS Y LIBERTADES

DOI: https://doi.org/10.20318/dyl.2021.5849

Número 44, Época II, enero 2021, pp. 41-79 
En realidad, el espíritu de los dos dictámenes a los que nos referimos y que no son partidarios de la prohibición generalizada (Consejo de Estado y Comité de Derechos Humanos de Naciones Unidas) viene a coincidir con buena parte de las críticas que se han realizado a la sentencia del TEDH en el referido asunto S.A.S. contra Francia y, de forma más amplia, a aquellas normativas prohibicionistas del uso del velo integral; incidiendo, para ello, en lo contraproducente de las medidas prohibicionistas con respecto a los objetivos declarados (integración, protección de la mujer...) y en que estas medidas normativas van dirigidas a proteger a una mayoría que siente su moral y estilo de vida afectados y declara verse insegura cuando se cruza con un velo. En este sentido, podemos recoger los trabajos de Eva Brems -de quien ya hemos citado su investigación empírica realizada en Bélgica con 27 mujeres que portaban el velo integral ${ }^{24}$. Mientras que, en nuestro entorno

párrafo 4, del Protocolo Facultativo, respecto de la comunicación núm. 2807/2016. En una nota al pie anterior ya hemos hecho referencia a estos dos dictámenes del Comité de Derechos Humanos de Naciones Unidas y hemos indicado dónde consultarlos. En la parte que recoge la deliberación de Comité en lo que respecta al "examen de la cuestión en cuanto al fondo", entre otras cosas, encontramos en ambos dictámenes la afirmación por parte del Comité de que no se ha explicado suficientemente por Francia la justificación y/o razonabilidad de la prohibición general del velo; también se observa que esta prohibición parece no tener en cuenta la posibilidad de que el uso de esta prenda pueda ser decidido por voluntad propia, incluso a modo de reivindicación; e, igualmente, se recogen los efectos negativos y contrarios a los pretendidos que podría tener la norma: "El Comité observa además que la prohibición, en lugar de proteger a las mujeres que usan el velo integral, podría tener el efecto contrario de confinarlas a su hogar, obstaculizar su acceso a los servicios públicos y exponerlas al riesgo de sufrir malos tratos y marginación". Por otra parte, también hay que recoger que estos dos dictámenes contaron con dos votos particulares concurrentes y dos disidentes, lo que no deja de poner también de manifiesto que nos encontramos ante una regulación poco pacífica.

24 Véase, E. BREMS, "Face veil bans in the European Court of Human Rights: the importance of empirical finding", Journal of Law and Policy, vol. 22 núm. 2, 2014, pp. 517-551, donde concluye: "Desde la perspectiva de las mujeres afectadas, las prohibiciones de los velos faciales son contraproducentes con respecto a los tres propósitos declarados para la prohibición: (1) restringen los derechos de las mujeres en lugar de promoverlos; (2) reducen la interacción social; y (3) exponen a las mujeres a graves riesgos de seguridad. Los legisladores francés y belga no estaban preocupados por el impacto del velo facial en las mujeres que lo llevaban, sino por el efecto en las personas que se encuentran con mujeres que lo llevan (...). ¿La sentencia S.A.S. versus Francia obligará a los Estados europeos a retirar las prohibiciones del velo facial? Si el Tribunal Europeo de Derechos Humanos se toma en serio la realidad empírica, no puede mantener las prohibiciones. Sin embargo, sigue existiendo el riesgo de que el Tribunal Europeo de Derechos Humanos no alcance a mirar a través de los ojos de un Otro tan diferente y que, simplemente, aceptará las justificaciones del Estado francés basadas 
-que tampoco ha estado exento de polémicas similares (Lleida y Reus) ${ }^{25}$-, entre otras aportaciones, también en una línea crítica Manuel Olmedo analiza esta sentencia del TEDH. De ella viene a decir que "se basa en un discurso argumentativo débil", con la consecuencia no deseable de suponer una limitación de derechos concretos e individuales reconocidos en el Convenio Europeo de Derechos Humanos, art. 8 y 9, en orden a satisfacer decisiones -y deseos- de la mayoría de "protegerse" en sus encuentros en el espacio público con mujeres que portan el velo integral. Como cierra Olmedo su trabajo: a través de esta sentencia, el TEDH "ha dado entrada, como limitación de los derechos y libertades de la minoría, y por la vía de la expresión 'derechos y libertades de los demás' de los arts. 8.2 y 9.2, a valores indeterminados y no positivizados (...) Podemos añadir que, lamentablemente, esos principios abstractos no son otra cosa que la condensación, en forma de pretendidos valores mínimos de convivencia, de la moral de la mayoría, identificación que ya sabemos puede dar lugar a comportamientos pretendidamente legítimos de intolerancia y xenofobia" 26 .

en supuestos ampliamente compartidos y preocupaciones mayoritarias, como lo han hecho el Consejo Constitucional francés y el Tribunal Constitucional belga"; pp. 550-551.

25 Sin ser ahora estos casos los que nos ocupan, cabe recordar aquí las ordenanzas cívicas de Lleida y Reus: la primera prohibía el uso del velo integral en equipamientos municipales; la segunda en espacios públicos. En relación al primer caso, aunque en un primer momento el Tribunal Superior de Justicia de Cataluña avalará la prohibición (STSJ CAT 5980/2011), posteriormente, el Tribunal Supremo acabó estimando un recurso de casación presentado por la Asociación Watani para la libertad y la Justicia y anulando la anterior sentencia en lo que se refiere a la Ordenanza Municipal de Civismo y Convivencia por exceder la potestad municipal y vulnerar el art. 16 de la Constitución Española, aunque habría que recoger que aceptó las cuestiones vinculadas con la identificación de los titulares de tarjeta de transporte recogidas en el art. 21 del Reglamento del Servicio de Transportes Urbanos (STS 693/2013). En el caso de Reus, fue el Tribunal Superior de Justicia de Cataluña quien -con base en la anterior sentencia del Supremo y a través de un Auto de 29 de enero de 2015- suspendió la ejecutividad de los artículos de la Ordenanza de Civismo de la ciudad de Reus que establecían esa prohibición (ATSJ CAT 1/2015). Por otro lado, resultan de interés las reflexiones que a partir de estas dos resoluciones del Tribunal Supremo y del Superior de Cataluña realiza Morondo sobre el uso del argumento de la igualdad y sobre la autonomía de las mujeres en los debates sobre el velo integral, véase: D. MORONDO, "El principio de igualdad entre mujeres y hombres frente a la prohibición del velo islámico integral", Anuario de Filosofía del Derecho, vol. XXX, 2014, pp. 291-307.

26 M. OLMEDO, "La sentencia del TEDH en el asunto S.A.S. c. Francia [GC], núm. 43835/2011, ECHR 2014, sobre la prohibición del velo integral en lugares públicos", Jueces para la democracia, núm. 83, 2015, pp. 102-115 (este mismo artículo se encuentra publicado en Diario La Ley, 8363, 2014). En un sentido similar, A. CARRETERO, “Sin burka por prohibición. 
En un similar sentido crítico con lo sustantivo de esta resolución del TEDH -y con la crítica ya comentada anteriormente en nota al pie a ese concepto jurídico indeterminado del "vivir juntos" en el que se apoya-, E. Relaño, tras afirmar que "en S.A.S. contra Francia el TEDH ha incurrido en un activismo judicial insano" al justificar una prohibición general en unas imprecisas exigencias de la convivencia social, concluye sobre estas regulaciones (la de Francia, Bélgica...y las que puedan venir): “El impacto de estas prohibiciones ha sido desproporcionado para un grupo determinado, las mujeres musulmanas, en flagrante violación del principio de no discriminación por motivos de conciencia, de religión y de género. No ha quedado demostrado que las prohibiciones hayan sido medidas necesarias y proporcionadas para la salvaguarda de la seguridad pública. Al contrario, esta legislación prohibitiva ha puesto de manifiesto hasta dónde puede el derecho doblegarse a la cultura del miedo y revestir a las presunciones, especulaciones y estereotipos de ropajes de apariencia jurídica, muy peligrosos para una democracia saludable y plural" 27 .

$Y$, finalmente, se nos antoja como suficientemente esclarecedora del significado de la resolución judicial del TEDH -y de la regulación prohibicionista- la reflexión aportada por Arzu Merali en torno a lo que supone esta imposición de los criterios de convivencia que el Gobierno francés define discrecionalmente: "En otras palabras, la solicitante individual y las portadoras individuales de niqab, de las que hay quizás miles, quedan reducidas a una masa y desprovistas de su capacidad de agencia individual en virtud de la ley, mientras que la masa de la comunidad, sin rostro concreto legalmente discernible, se considera individual y capaz de experimentar sentimientos susceptibles de ser heridos. La (supuesta) mayoría blanca es, en consecuencia, el ciudadano francés modelo, y quien incumpla la prohibición se considera una delincuente a la que es necesario sancionar mediante una multa y/o la obligación de acudir a clases de ciudadanía" 28.

Con todo lo anterior, coincidimos en plantear que, incluso pensando en un legislador bienintencionado, el resultado de una norma prohibicionista y

Nota a la sentencia del Tribunal Europeo de Derechos Humanos de 1 de julio de 2014", Revista CESCO de Derecho de Consumo, núm. 11, 2014, pp. 273-285.

27 E. RELAÑO, "Las dos caras del Dr. Jekyll: las prohibiciones del velo integral a debate", Debates Jurídicos, núm. 5, abril-2015, pp. 1-33 (último acceso en diciembre de 2019 a través de la sección "publicaciones" de: www.rightsinternationalspain.org).

28 A. MERALI, "Vivir como un Ser social. La interconectividad del ser", trad. C. Piña, en B. DE SOUSA SANTOS y B. SENA MARTINS (eds.), El pluriverso de los derechos humanos. La diversidad de las luchas por la dignidad, Akal, Ciudad de México, 2019, p. 134. 
sancionadora de este tipo nos lleva a considerar que lo que en abstracto puede ser una medida político-jurídica que trata de corregir la desigualdad -y la discriminación (o subordiscriminación) ${ }^{29}$ - generada por una visión del mundo que tiene como regla la dominación de un sexo sobre otro, puede acabar provocando efectos no deseados: clausura y estigmatización de la mujer musulmana, representación hostil de la identidad, humillación, radicalización y cierre identitario y, entre otros, y no exento de importancia, riesgo de desubjetivización. En este sentido, más contundente resulta De Féo, para quien -más allá de la consideración de "riesgo de" - la ley sería reflejo de un discurso público construido sobre estereotipos que reducen a estas mujeres a una condición de víctimas de un orden patriarcal y les impiden su desarrollo como sujetos de pleno derecho que toman decisiones individuales; esto es, con el protagonismo de esta ley que prohíbe -y el refuerzo de los medios de comunicación- plantea esta investigadora que se somete a las mujeres portadoras del velo integral a un proceso de desubjetivización donde se les confisca la palabra, se les condiciona su capacidad de elegir, se les niega su libre albedrío y su individualidad y se les encierra, en definitiva, en una prisión simbólica ${ }^{30}$.

Dejando reservado este tema de la desubjetivización -que luego retomaremos-, en su conjunto, se trata de efectos que creo tienen que ver con la

29 "Subordiscriminación" atendiendo a la propuesta terminológica y conceptual que en nuestro entorno académico trabajan Barrère y Morondo y que nos remite a considerar la discriminación dentro, y en términos de, sistemas de opresión y dominación, véase M. Á. BARRÈRE, y D. MORONDO, “Subordiscriminación y discriminación interseccional: elementos para una teoría del derecho antidiscriminatorio", Anales de la Cátedra Francisco Suárez, núm. 45, 2011, pp. 15-42.

30 En todos o algunos de los efectos negativos arriba señalados vienen a coincidir los trabajos que analizan con perspectiva crítica la norma francesa y la sentencia del TEDH. Conviene, no obstante, hacer mención individualizada de A. DE FÉO, "Les femmes en niqab en France", Socio, núm. 11, 2018, pp. 141-164, quien, además de referirse a los efectos arriba recogidos como "efectos controvertidos de la ley", se centra en la cuestión de la desubjetivización. Por otra parte, también resulta oportuno, cuando menos, mencionar aquí otros planteamientos que ayudan a matizar la afirmación de estos efectos de "desubjetivización". Es el caso de los argumentos de M. MALIK, "El derecho de la igualdad: resolviendo conflictos de igualdad y derechos humanos. La experiencia británica", cit., pp. 109-146, donde se traslada el debate desde la posible pérdida de la condición de sujeto a la de los límites de los derechos -una cuestión ya apuntada en el texto anteriormente- y donde la autora nos abre la mirada y, tal vez, nos permita un "punto de fuga" en la siguiente afirmación: "El problema de los símbolos religiosos como el del velo se presenta como un conflicto irresoluble entre la religión y el género, cuando en realidad se trata de problemas de discriminación múltiple y de interseccionalidad" (p. 127). 
dinámica generada por la existencia de la norma. Son efectos tal vez buscados o tal vez no, pero vinculados con la existencia de una norma que en su diseño no parece ser consciente del contexto en el que no solo se desarrolla, sino en el que podríamos decir que se haya atrapada y en el que encontramos cuestiones como las siguientes: que la identidad se ha convertido en nuestras sociedades en un importante factor de estratificación (con consecuencias de creación de estereotipos, segregación, humillación, estigmatización...), por lo que no se puede ignorar la cuestión de la identidad ni qué tratamiento jurídico-político se hace de las cuestiones a ella vinculadas; que, precisamente, este derecho y esta política se mueven, y alcanzan su significado, en un terreno de desconfianza y mixofobia desde donde se reclama que las sociedades se clausuren ante el exterior y ante los extraños que se han colado entre nosotros, favoreciendo la diferenciación y separación y reforzando el nosotros a costa de mantener limpios, sólidos e inexpugnables los muros y barreras que nos separan del ellos, del otro; o, entre otras cuestiones que contextualizan, que el derecho y las políticas de igualdad que podrían vincularse con esta norma no están exentos de acabar leyéndose como un refuerzo antiséptico del que tienden a rodearse las "comunidades de mismidad", comunidades inclinadas a refugiarse en definiciones-construcciones cerradas del nosotros ante la ansiedad y el temor que les provoca la necesidad de convivir con una creciente variedad de tipos y estilos de vida, renunciado a cualquier esfuerzo por comprender la diferencia y negociar en sociedades complejas ${ }^{31}$.

De este modo, regresando a la idea de la desigualdad existencial, así como a estos efectos "no deseados" que apuntábamos, y en especial al riesgo de desubjetivización en lo que significa de negación del estatus de sujeto a una persona, creo que es relevante traer aquí, con este caso, que conviene entender

31 Sobre estas cuestiones que condicionan el significado que le demos a cualquier política y desarrollo normativo en este ámbito: sobre el valor de la identidad como factor de estratificación; la desconfianza y mixofobia que definen el contexto y que animan a la clausura de las sociedades ante el exterior; y la lectura de las políticas y medidas normativas como un refuerzo antiséptico funcional a las "comunidades de mismidad", sirvan, entre otros trabajos del mismo autor: Z. BAUMAN, Comunidad. En busca de seguridad en un mundo hostil, trad. J. Alborés, Siglo XXI, Madrid, 2003; Id., Identidad, trad. D. Sarasola, Losada, Madrid, 2005; Id., Confianza y temor en la ciudad. Vivir con extranjeros, trad. J. Sempere y E. Tudó, Arcadia, Barcelona, 2006; Id., Mundo consumo. Ética del individuo en la aldea global, trad. L. Mosconi, Fondo de Cultura Económica, Madrid, 2010. Por otra parte, sobre "el valor del extraño" como ayuda para comprender el significado de estas iniciativas jurídico-políticas, puede verse: R. SUSÍN, "Inmigración y barreras en la ciudadanía. El miedo al otro y el derecho a la democracia plural”, Anuario de Filosofía del Derecho, vol. XXXI, 2015, pp. 234-244. 
que cubrirse con velo -o enseñar todo lo posible- debe ser un ejercicio de libertad y, por eso, puede defenderse que no es tanto el velo lo que conculca la libertad de estas mujeres, sino la imposición de prescindir de él, les guste o no ${ }^{32}$. Como bien recogía ya hace unos años Ferrajoli al hilo de unas reflexiones sobre la relación entre el carácter universal de los derechos fundamentales y el multiculturalismo -y tras advertir de la importancia de que en casos como el del velo y, más aún, en otros como el de la infibulación, la regulación debe ir encaminada a la protección de las personas "de carne y hueso", al individuo, y no a la cultura-: "Siempre que se produzca cualquier coacción de su ejercicio en forma de obligación o de prohibición estaremos en presencia de la imposición jurídica de una determinada cultura -nuestra moral y nuestra cultura, asumidas de hecho como la única o la verdadera moral o cultura- que contradice los principios de libertad y laicidad en nombre de los cuales tales obligaciones o prohibiciones son impuestas" 33 .

Dicho de otra forma, podríamos preguntarnos: ¿qué ofende más la dignidad de las mujeres?; ¿qué las hace más desiguales e inferiores?: ¿el más

32 Como plantea Leila Slimani, escritora ganadora del Goncourt 2016 y activista feminista franco-magrebí, el velo solo desaparecerá "cuando las mujeres por sí mismas, con la educación, el feminismo, con otra relación con sus cuerpos, sientan menos necesidad de portarlo (...). Aprecio mucho la laicidad, creo que es un lujo extraordinario vivir en un país laico donde cada cual guarda para sí su religión. Pero mientras la gente respete la laicidad y no busque convencer a todo el mundo, tiene derecho a vivir su religión como quiera"; El País de 31 de octubre de 2019. También nos sirven aquí las consideraciones sobre estas normas prohibitivas y la autonomía de las mujeres, en el marco de una reflexión sobre el significado del velo, de C. GARCÍA PASCUAL, "Ciudadanía y vida social bajo el velo integral", Cuadernos Electrónicos de Filosofía del Derecho, núm. 33, 2016, pp. 42-67, donde, además, concluye: “El burka o el niqab no deberían encontrar espacio en nuestras ciudades de la misma manera que no debería encontrar espacio la discriminación, la desigualdad, la explotación. Pero construir una sociedad libre a través de leyes prohibitivas o sancionadoras no constata nada más que el fracaso de todo lo que hubiera debido realizarse antes en pos de la igualdad" (p. 66).

33 En ese trabajo alertaba Ferrajoli de los efectos negativos del tratamiento penal con respecto a la infibulación, pero también sobre el tema del velo: “...por más estigmatizable que sea en el plano moral y político como signo de una subordinación de la persona y de una mortificación de su dignidad, siempre que sea el producto de una elección libre y consciente por parte de una mujer mayor, no se justifica castigarla (...). Más bien, ya que son con frecuencia bastante más eficaces, deberán existir los instrumentos para prevenir estas prácticas intolerables, sobre las que la represión penal tendría el único efecto de hacerlas clandestinas e incluso de incentivarlas como actitud de defensa de una identidad cultural ofendida: se requiere la educación, la persuasión y, en general, todas las políticas dirigidas a la emancipación de la mujer"; L. FERRAJOLI, "Derechos fundamentales: universalismo y multiculturalismo", trad. M. Carbonell, Claves de Razón Práctica, núm. 184, 2008, pp. 4-7.

ISSN: 1133-0937

DERECHOS Y LIBERTADES

DOI: https://doi.org/10.20318/dyl.2021.5849

Número 44, Época II, enero 2021, pp. 41-79 
tupido de los velos o no escucharlas y declararlas esclavas de lo irracional? O como también se ha planteado, igual resulta prudente pensar que aunque el burqa o el niqab -incluso, el hiyab, aun con las diferencias que existen y que conllevan valoraciones diferentes ${ }^{34}$ - puedan ser en realidad elementos que revelan una situación de subordinación femenina y de ejercicio de poder y dominación masculina, la regulación sobre su uso (y no tanto el pañuelo en sí), ya sea obligando en unos países o prohibiendo en otros, no deja de ser, de una parte, una normativización del cuerpo de las mujeres musulmanas; y de otra, y en cierta medida yendo más lejos, un intento por establecer el control, la subordinación y la dominación de todos los musulmanes por medio de estas reglas normalizadoras ${ }^{35}$. En este sentido, puede ser de interés acudir a la reflexión de Carme Adán cuando reivindica la conveniencia de "legislar como feministas" -que no es lo mismo, sostiene, que una "legislación feminista" -, y tras preguntarse si prohibir la prostitución mejorará la vida de las mujeres que la ejercen y afirmar que "el problema sigue siendo la masculinidad heteropatriarcal construida sobre el desprecio y el control del cuerpo femenino", se refiere al hiyab (del que -aunque aquí nos sirve la cita- insisto soy consciente de que requiere de un tratamiento y tiene un significado diferente al del velo integral) y dice: “Aquí el hiyab también es algo más que un pañuelo, y la prohibición de entrar con él en las aulas tampoco parece muy liberadora. En este conflicto siempre da la sensación de que la joven carece de capacidad para decidir, que alguien tiene que hablar por ella (...). En muy pocas ocasiones estamos dispuestas a escuchar cuál es la opinión de las mujeres musulmanas. Adoptamos una posición eurocéntrica de superioridad, como si no tuviéramos ataduras y sumisiones de sobras visibles en nuestro

34 C. GARCÍA PASCUAL, "Ciudadanía y vida social bajo el velo integral”, cit., pp. 4267, aporta un elemento de interés en esta diferenciación, apuntando no solo que el debate más reciente sobre el velo integral y su prohibición "ha redimensionado" el que hubo en su día sobre el hiyab, sino, sobre todo, que aunque los dos podrían leerse como símbolos de desigualdad, mientras el hiyab admite una resignificación, esta no cabe en el caso del velo integral o "no cabe una que permita a las mujeres participar plenamente en la vida pública" debido a su potencial excluyente (incluso, habiendo voluntariedad) (p. 62).

35 En este sentido, resulta reveladora la reflexión crítica siguiente: "La regulación del pañuelo se convierte en un dispositivo visible del apuntalamiento de la desigualdad entre un ellos y un nosotros. Normativizando el cuerpo de los otros se hace evidente la relación de dominación, ya que se está imponiendo un modo de representación, a través de la implantación de una imagen a la que el sujeto tiene que parecerse o asimilarse: no hay que o hay que llevar el pañuelo"; Á. RAMÍREZ, La trampa del velo. El debate sobre el uso del pañuelo musulmán, Los libros de la catarata, Madrid, 2011, p. 144. 
propio cuerpo para ir dándoles lecciones de libertad a quienes ni siquiera nos las han pedido" ${ }^{36}$.

Así, con lo anterior podemos concluir este apartado diciendo que con el derecho y las políticas públicas, en un sentido o en otro, prohibiendo el uso del velo integral $u$ obligando a ello, no se hace otra cosa que participar de una dinámica de reificación y normativización del cuerpo del otro. A este otro -normalmente a esta otra- le imponemos la imagen que debe cumplir, a la que debe asimilarse, pero, al mismo tiempo, al señalarlo lo convertimos en un "exterior constitutivo" y con ello apuntalamos la desigualdad entre nosotros y ellos ${ }^{37}$; y no solo la desigualdad, también toda una más compleja arquitectura de opresión y dominación. En definitiva, lo que en principio podría ser pensado como una intervención jurídica que sirviera para corregir, o atenuar, una situación de discriminación acaba reforzando una situación -en la expresión ya referida de Barrère y Morondo- de subordiscriminación.

\section{PROPUESTA DE TRATAMIENTO DE LAS DESIGUALDADES COMPLEJAS Y ENTRELAZADAS}

\subsection{Qué no conviene hacer}

Partiendo de que no conviene caer en reconocimiento de inconmensurabilidad alguna que nos lleve a un relativismo asocial, creo que podemos avanzar afirmando que se requiere, sin duda, una actuación jurídica política, pero no cualquiera. Esto es, no parece posible renunciar a la utilización del derecho y las políticas públicas para actuar sobre desigualdades, discriminaciones y subordiscriminaciones, pero habrá que ser cuidadoso en la opción

36 C. ADÁN, Feminicidio. Un nuevo orden patriarcal en tiempos de sumisión, Edicions Bellaterra, Barcelona, 2019, pp. 117-119. Con resultados distintos y en este caso como límite a la diversidad cultural y religiosa, también se propone para este tema atender a la dimensión de género en: O. SALAZAR, "La autonomía relacional de las mujeres como límite de la diversidad cultural y religiosa: a propósito de la polémica prohibición del veo integral", Derechos y Libertades, núm. 34, 2016, pp. 203-234.

37 Se trata de disponer de un fobotipo de lo propio, de un "exterior constitutivo" que facilite la estrategia de "clausura del sentido" de la sociedad ante el mundo exterior, manteniendo su identidad y cohesión interna en la precisa diferenciación con lo que le rodea; H. SILVEIRA GORSKI, "Introducción: La vida en común en sociedades multiculturales. Aportaciones para un debate", Id. (ed.), Identidades comunitarias y democracia, Trotta, Madrid, 2000, pp. 11-43. 
elegida, no sea que el efecto final resulte ser el del fortalecimiento de aquello que queremos corregir.

Por lo tanto -y aunque no por sabido deje de ser necesario recordarlo-, no cabe recurrir -a través de la vía de la infrapenalidad y micropenalidad que supone el derecho administrativo sancionador- a un populismo punitivo que, si bien dice que persigue aportar seguridad, su resultado final es el de producir el efecto contrario: acabar generando más violencia e inseguridad. Sin entrar en el detalle que requeriría esta cuestión, lo que quiero decir aquí es que hay que evitar actuaciones sancionadoras que participan de la dinámica de un populismo punitivo que se justifica en procurar una seguridad pública libre de las amenazas que nos genera el extraño y sus costumbres bárbaras; cuando, por el contrario, acaba por facilitar la consumación de una especie de profecía autocumplida en la que la regresión cívica y democrática, la estigmatización, segregación y aislamiento que provoca sirven de caldo de cultivo para la violencia, la criminalidad, el desorden, el incivismo... en definitiva, para el grave deterioro del tejido social sobre el que se deben asentar las sociedades que se pretenden democráticas ${ }^{38}$.

Como digo, es una cuestión que requiere más tiempo del que ahora disponemos, pero, cuando menos, sí que conviene recoger dos cosas más que creo de interés para este trabajo. De una parte, no podemos ignorar que este populismo punitivo se conecta, de alguna manera, con el hecho de que hayamos decidido renunciar a la potencialidad de la ciudad como lo que siempre ha sido: un lugar de encuentro y de diálogo entre experiencias diversas. $Y$, frente a esto, la hayamos reconvertido en un espacio que nos provoca ansiedad en la medida en que la obsesión por habitar espacios homogéneos, excluyentes y exclusivos, nos arrastra a una incapacidad para convivir entre extraños y de allí a una reacción de paranoia mixofóbica ${ }^{39}$; lo que, además,

38 "El populismo penal se compagina con el populismo político: inculcando y alimentando el miedo, la sospecha y la percepción del diverso -del emigrado, del negro, del islamista- como enemigo, deformando el sustrato simbólico de la democracia que es el sentimiento común de igualdad y de solidaridad, sustituyéndolo por el sustrato simbólico de los regímenes populistas y autoritarios"; L. FERRAJOLI, "Democracia y miedo", trad. J. M. Revuelta, en M. BOVERO y V. PAZÉ (eds.), La democracia en nueve lecciones, Trotta, Madrid, pp. 2014, pp. 112-113.

39 "La paranoia mixofóbica es un círculo vicioso que actúa como una profecía que lleva en sí el germen de su cumplimiento. Si se ofrece y se acepta la segregación como si fuera un remedio radical para el peligro que representan los extranjeros, la convivencia con ellos se vuelve más difícil cada día. Homogeneizar los barrios, y después reducir al mínimo inevitable todo comercio y comunicación entre ellos, es la fórmula infalible para avivar e intensificar el deseo de excluir y segregar. Semejante medida puede contribuir a aliviar los dolores que 
pone sobre la mesa cómo el espacio urbano, el diseño de nuestras ciudades, tiene implicaciones éticas y condiciona nuestras vidas ${ }^{40}$. Mientras que, de otra parte y vinculado con el significado del espacio público como instrumento ideológico ${ }^{41}$, conviene insistir en que este populismo punitivo no se desarrolla únicamente a través de lo que podemos conocer como el "Gran Derecho", el derecho penal; también, y sobre todo para estos casos, el derecho administrativo sancionador se muestra como una opción para garantizar la convivencia pacífica y ordenada en lo que, de inicio, aparece como un terreno hostil. Intervenciones legislativas que tienen el mismo aspecto de legalidad que el derecho penal, pero que, aparentemente, son menos lesivas (y también peligrosamente menos garantistas), se defienden como formas de promoción de la convivencia; aunque, en el fondo y a través de su dinámica de identificación excluyente, no dejan de cumplir con funciones de control, censura, intimidación y represión de poblaciones que consideramos inconvenientes ${ }^{42}$.

Dejada a un lado esta opción de tratamiento jurídico-político, creo que tampoco cabe recurrir a iniciativas que sigan los dictados en abstracto de los expertos. Iniciativas que habiliten a una especie de monopolio de toma de decisiones por parte de los expertos sin tener en consideración la opinión de los sujetos afectados y sus características particulares. Una opinión que precisamente por la vulnerabilidad de estos sujetos se hace más necesario tener en cuenta para corregir su tendencia a la invisibilidad y, desde allí, los riesgos de discriminación. No cabe, igualmente, y esto es importante en lo que nos ocupa, refugiarse en máximas como la de "ninguna diferencia sin igualdad", necesarias -e ineludibles en cualquier tratamiento que aspire, desde la honestidad, a ser calificado de justo-, pero no suficientes como principios de actua-

padecen las personas aquejadas de mixofobia, pero el remedio es patógeno en sí mismo y empeora el sufrimiento, por lo que siempre se requieren dosis más fuertes de la medicina para que el dolor sea soportable"; Z. BAUMAN, Confianza y temor en la ciudad. Vivir con extranjeros, cit., pp. 37-38.

${ }_{40}$ Resultan de interés las reflexiones que sobre las implicaciones ética-urbanismo encontramos en R. SENNET, Construir y habitar. Ética para la ciudad, trad. M.A. Galmarini, Anagrama, Barcelona, 2019, donde este autor concluye: “La conexión ética entre el urbanista y el urbanita reside en la práctica de cierto tipo de modestia, en vivir entre muchos asumiendo el compromiso con un mundo que no es el espejo de uno mismo", p. 384.

${ }_{41}$ M. DELGADO, El espacio público como ideología, $2^{\mathrm{a}}$ ed., Los libros de la Catarata, Madrid, 2015.

42 Sobre estas cuestiones, véanse los trabajos recogidos en P. OLIVER (coords.), Burorrepresión. Sanción administrativa y control social, ed. Bomarzo, Albacete, 2013, sobre todo, los firmados por M. MAROTO (pp. 29-64) y Ó. J. MARTÍN (pp. 65-93). 
ción en una sociedad plural, sobre todo, si queremos evitar riesgos asimilacionistas. $\mathrm{Ni}$, en este mismo sentido, tampoco cabe quedarse anclado en derechos o políticas públicas que tienen como única referencia concepciones estándar de la igualdad ajenas a la pluralidad de nuestras sociedades e insensibles a comprender que desigualdad y discriminación, de un lado, y diferencia, de otro, no son comparables ni tienen el mismo valor, cobrando así sentido el reconocimiento de esta última en la construcción de una sociedad justa ${ }^{43}$.

Sin embargo, con lo anterior, conviene reparar que tampoco estamos diciendo que la opción deba ser la de desnivelar nuestra posición de manera incondicional hacia lo que se conoce como "políticas de identidad", con el riesgo de reificación y aislamiento que ello conllevaría y del que nos advierte Nancy Fraser. En su apuesta por una concepción bidimensional de la Justicia -que admite "al menos dos dimensiones analíticamente distintas": redistribución y reconocimiento ${ }^{44}$-, Fraser señalaba dos problemas en torno al reconocimiento: el problema del desplazamiento, que tiene que ver con cómo "las cuestiones de reconocimiento sirven menos para complementar, hacer más complejas y enriquecer las luchas redistributivas que para marginarlas, eclipsarlas y desplazarlas"; y lo que denomina el problema de la reificación: "Las vías que a menudo toman estas luchas (en favor del reconocimiento) sirven no ya para promover una interacción respetuosa en contextos cada vez más multiculturales, sino para simplificar y reificar drásticamente las identidades de grupo. Tienden, más bien, a alentar el aislamiento, la intolerancia y el chovinismo, el patriarcado y el autoritarismo" ${ }^{45}$.

43 En este sentido, resultan de interés las reflexiones sobre la igualdad y la propuesta de revisión de lo que denomina concepción estándar del principio de igualdad (CEPI) que encontramos en L. VILLAVICENCIO MIRANDA, "Justicia social y el principio de igualdad", cit., pp. 43-74, donde identifica tres ámbitos de exclusión de esta CEPI: la opresión estructural del proletariado; las diferencias culturales no reconocidas en el Estado nacional unitario; y las diferencias de género. $Y$, finalmente, propone una idea revisada de la igualdad que afronte los desafíos de la incorporación de las diferencias y las políticas de reconocimiento; de las críticas feministas; de la falta de una perspectiva interseccional; y de la persistencia estructural del particularismo.

44 N. FRASER, “Repensar el reconocimiento. Superar el desplazamiento y la reificación en la política cultural", en $\mathrm{M}^{\mathrm{a}}$. A. CARBONERO GAMUNDÍ y J. VALDIVIESO (eds.), Dilemas de la Justicia en el siglo XXI. Género y globalización, cit., p. 320 (reedición en castellano de un artículo publicado en New Left Review, núm. 3, 2000, pp. 107-120), donde, en una nota al pie, Fraser ya adelanta que habría detectado, junto a los obstáculos económicos y culturales, un tercer tipo de obstáculos, los políticos, que requieren pensar en una tercera dimensión de la justicia social, la representación, que luego desarrollará en Escalas de la justicia.

45 Ibidem, p. 310. 
Ocupándonos de este segundo problema, el peligro que se quiere destacar es que la reificación de la identidad supone "elaborar y exhibir una identidad colectiva auténtica, autoafirmadora y autogenerada" desde la que, a su vez, se ejerce una presión moral sobre cada sujeto individual para conformarle a la cultura de un grupo determinado. El resultado de todo ello, como denuncia Fraser, viene a ser el de la anulación de todo vestigio de crítica y disidencia, la imposición de "una única identidad de grupo drásticamente simplificada que niega la complejidad de la vida de las personas, la multiplicidad de sus identificaciones y las dispersiones de sus distintas afiliaciones". Y como acierta a concluir en su crítica de este efecto de reificación de la identidad: "Irónicamente, entonces, el modelo de la identidad sirve como vehículo para el mal reconocimiento: al reificar la identidad de grupo, acaba oscureciendo la política de la identificación cultural, las luchas dentro del grupo por la autoridad -y el poder-de representarlo. Al ocultar estas luchas, este enfoque enmascara el poder de las fracciones dominantes y refuerza la dominación intragrupal. El modelo de la identidad se presta así con demasiada facilidad a las formas represivas de comunitarismo, promoviendo el conformismo, la intolerancia y el patriarcado" 46 .

O como de forma algo más completa propone en otro trabajo Fraser donde reflexiona sobre cómo el postfordimo, el poscomunismo y la globalización han determinado una coyuntura en la que el centro de gravedad de la cultura política se ha desplazado de la redistribución al reconocimiento-, se trataría de destacar tres tendencias políticas "que, si no se revisan, pueden amenazar el proyecto de integración de la redistribución y el reconocimiento": los ya citados problemas de reificación y desplazamiento, al que añade el desencuadre, que tiene que ver con los efectos renacionalizadores como res-

46 Ibidem, p. 315. En relación con lo arriba recogido, Bauman ya hace unos años alertaba sobre que existía una tendencia a transformar la multiculturalidad en multicomunitarismo. Lo que lleva a que las diferencias culturales sean utilizadas como "materiales de obra en la frenética construcción de muros defensivos y rampas de lanzamiento de misiles"; y de allí concluye que "la 'cultura' se convierte en sinónimo de fortaleza asediada, y en una fortaleza sitiada se exige a sus habitantes que manifiesten diariamente su lealtad inquebrantable y que se abstengan de cualquier trato familiar con los de fuera", manifestación también, en cualquier caso, de la citada reificación que viene a ocultar, y a reforzar, la dominación intragrupal; Z. BAUMAN, Comunidad, cit., p. 166. También, en otro sentido, puede ser interesante recoger la crítica que a las políticas de identidad contemporáneas realiza Asad Haider, incidiendo en su punto de partida de demandas identitarias individuales de reconocimiento y en sus efectos conformistas y de neutralización de movimientos contra la opresión; A. HAIDER, Mistaken identity. Race and class in the age of Trump, Verso, London, 2018, pp. 7-26. 
puesta a procesos que superan ese marco nacional. $Y$, señaladas estas cuestiones, concluye que se trata de tres problemas "extremadamente graves" que amenazan con "hacer descarrilar el proyecto de integrar la distribución y el reconocimiento en un marco político global" ${ }^{47}$.

\subsection{Redistribución y reconocimiento (y representación)}

Estas advertencias de Fraser sobre los riesgos de las políticas de reconocimiento se enmarcan, en realidad, en su propuesta por superar la falsa antítesis redistribución o reconocimiento, su construcción "como alternativas mutuamente excluyentes" que nos obliga a una elección; en su detección de colectivos subordinados bivalentes en los que cabe hablar tanto de mala distribución como de mal reconocimiento; y, como continuidad lógica de lo anterior, en su reivindicación de la necesidad de integrar ambas dimensiones en un único marco comprehensivo de tal manera que, como afirma, podamos "satisfacer los requisitos de justicia para todos". Además, esta defensa de lo que la autora llama concepción bidimensional de la justicia se completa con lo que presenta como su núcleo normativo: "la noción de paridad de participación" -adelanto de lo que luego desarrollará en su propuesta tridimensional como la dimensión representación ${ }^{48}$ - que establece que "la justicia precisa de disposiciones sociales que permitan a todos los miembros adultos de la sociedad interactuar como pares"; y que requiere del cumplimiento de "la condición objetiva" (una distribución de recursos materiales que asegure la independencia y voz de los participantes) y de "la

47 N. FRASER, “La justicia social en la era de la política de la identidad: redistribución, reconocimiento y participación", en N. FRASER y A. HONNETH, ¿Redistribución o reconocimiento?, trad. P. Manzano, edic. Morata y Fundación Paideia Galiza, Madrid-A Coruña, 2006, pp. 85-88, donde dice sobre estos tres problemas: "En la medida en que la política de reconocimiento está cosificando identidades colectivas, corre el riesgo de sancionar violaciones de derechos humanos y congelar los antagonismos entre los que pretende mediar. En la medida en que desplaza la política de redistribución, puede estar promoviendo, en realidad, la desigualdad económica. Por último, en la medida en que las luchas de cualquier tipo están desencuadrando los procesos transnacionales, corren el riesgo de truncar el alcance de la justicia y excluir a actores sociales relevantes".

48 Como hemos apuntado en una nota al pie anterior, será en Escalas de la Justicia donde se desarrolle esta tercera dimensión, la representación, continuidad de la noción de paridad de participación. Sobre esta continuidad entre las obras de Fraser ¿Redistribución o reconocimiento? y Escalas de la Justicia, véase C. IGLESIAS, "Justicia como redistribución, reconocimiento y representación: Las reconciliaciones de Nancy Fraser", Investigaciones Feministas, núm. 3, 2012, pp. 251-269. 
condición intersubjetiva" (unos patrones institucionalizados culturales que constituyan a los actores como pares, que expresen igual respeto y aseguren igualdad de oportunidades) ${ }^{49}$.

Siguiendo con Fraser y su compleja tarea de integrar redistribución y reconocimiento, lo anterior conformaría, junto a lo que denomina el modelo de estatus de reconocimiento, la parte correspondiente a la dimensión filosóficomoral; a lo que habría que añadir las cuestiones propias de la teoría social y a estas las de la teoría y la práctica política. Con respecto a las primeras, "la tarea principal consiste en comprender las relaciones entre la mala distribución y el reconocimiento erróneo en la sociedad contemporánea"; es decir, avanzar en una teoría crítica de la sociedad contemporánea en la que se incluya una explicación de la relación de subordinación de estatus con la subordinación de clase social, sin reducir ni aquel a esta ni esta a aquel y asumiendo la existencia de conexiones entre la distribución y el reconocimiento. Y a esto habría que sumar las cuestiones políticas que surgen en el intento de conseguir la concepción integradora de la justicia a través de la institucionalización de reformas tendentes a reparar las situaciones de injusticia de clase y de estatus, de redistribución y reconocimiento, al mismo tiempo ${ }^{50}$.

Fijando la mirada en la necesidad de repensar la política de reconocimiento más allá de cualquier opción que suponga una reificación de la identidad,

${ }^{49}$ Véase N. FRASER, “Redistribución, reconocimiento y participación. Hacia un concepto integrado de justicia”, en Ma . A. CARBONERO GAMUNDÍ y J. VALDIVIESO (eds.), Dilemas de la Justicia en el siglo XXI. Género y globalización, cit., pp. 291-308 (reedición en castellano de un artículo publicado en World Culture Report 2000, Cultural Diversity, Conflict and Pluralism, UNESCO Publishing, Paris, 2000, pp. 48-57). Véase también, N. FRASER, “La política feminista en la era del reconocimiento. Un enfoque bidimensional para la justicia de género", en Ma . A. CARBONERO GAMUNDÍ y J. VALDIVIESO (eds.), Dilemas de la Justicia en el siglo XXI. Género y globalización, cit., pp. 325-344 (reedición en castellano de un artículo publicado en Studies in Social Justice, núm. 1, vol. 1, 2007, pp. 23-35), donde trabaja su propuesta de justicia bidimensional integradora de redistribución y reconocimiento desde una perspectiva de género y clarifica su utilización del elemento clave que supone el principio de paridad de participación, diferenciándolo de lo que llama la parité francesa.

50 Al margen de que sobre la concepción bidimensional de la justicia encontramos numerosas referencias en los trabajos de Fraser, y entre ellos en los citados en este artículo, sobre estas cuestiones cabe destacar la versión más extensa: N. FRASER, “La justicia social en la era de la política de la identidad: redistribución, reconocimiento y participación”, cit., pp. 17-88, donde recoge su crítica a la "falsa antítesis" redistribución-reconocimiento y su desarrollo de las cuestiones filosóficas normativas referentes a la relación de esas dos categorías (pp. 17-51), que amplía con cuestiones propias de teoría social, problemas políticos y unas reflexiones coyunturales finales (pp. 51-88). 
resulta oportuno recurrir al ya citado modelo de estatus de reconocimiento que nos presenta Nancy Fraser. Para esta autora, su propuesta significa que "lo que requiere el reconocimiento no es una identidad específica de grupo sino el estatus de los miembros individuales del grupo como socios plenos en la interacción social"; esto es, siendo necesario el reconocimiento para superar las situaciones de injusticia, la perspectiva que se trabaja desde el modelo de estatus no se limita a la identidad, sino que "significa una política dirigida a superar la subordinación constituyendo a la parte mal reconocida como pleno miembro de la sociedad, capaz de participar como par con los demás". Pero además, y esto es importante -en línea con esta visión integradora de la justicia a la que nos referimos-: el modelo de estatus no solo se preocupa por corregir el riesgo de reificación, también se muestra alerta frente al de desplazamiento, planteando que distribución y reconocimiento, pese a estar asociadas a dimensiones analíticas diferentes del orden social y de la (in)-justicia, "están imbricadas e interactúan causalmente entre sí" 51 .

Más en concreto, conviene hacer mención a cómo en su propuesta de modelo de estatus de reconocimiento -y en ella a través de la norma de la paridad participativa- Fraser se refiere al "asunto del velo" que antes, sobre todo en su versión de velo integral, nos ocupaba. Así, de un lado, recoge cómo reivindicaciones de reconocimiento cultural y religioso con el modelo de estatus, frente al modelo de autorrealización, tendrían justificación si superasen el doble requisito de que los reclamantes demostrasen que "la institucionalización de las normas de la mayoría cultural les niega la paridad participativa" -nivel intergrupal-, y que "las prácticas cuyo reconocimiento se busca no niegan la paridad participativa" -nivel intragrupal-. Considerada la controversia francesa sobre el uso del velo islámico en las escuelas públicas ( $\mathrm{y}$, en cierta medida y guardando la debida distancia, podríamos ampliar al uso del velo integral en el espacio público), en primer lugar, aunque Fraser no parece tener en cuenta que la prohibición de 2004 se extiende a todos los símbolos religiosos ostensibles o llamativos, es cierto que hay una mayor focalización de hecho en el velo islámico (por algo esta norma también es conocida popularmente como "ley del velo" 52), lo que podría seguir haciendo válido su comentario de que la norma "niega la igualdad de categoría a los ciudadanos musulmanes". Mientras

51 Sobre este modelo de reconocimiento de estatus como alternativa al de la identidad, véase N. FRASER, “Repensar el reconocimiento. Superar el desplazamiento y la reificación en la política cultural", cit., pp. 316-324.

52 Se trata de la conocida como ley de la laicidad o del velo, Ley 2004-228, de 15 de marzo de 2004, que, en aplicación del principio de laicidad, introduce en el Código de educación 
que, en segundo lugar -aunque admite que discutible-, cabe que, alejados de interpretaciones "en un sentido patriarcal unívoco", el uso del velo en sí no suponga subordinación de la mujer y quepa la posibilidad de tratar el velo "como un símbolo de la identidad musulmana en transición", en proceso de discusión, "a consecuencia de las interacciones transculturales en una sociedad multicultural"; lo que llevaría a entender que autorizar el uso del velo (en escuelas y espacios públicos) "podría ser un paso adelante, y no hacia atrás, con respecto a la paridad de género" ${ }^{53}$. Con esto, a través del ejemplo del velo, Fraser trata de explicar cómo el modelo de estatus y la paridad de participación se presentan como "el estándar apropiado para garantizar las reivindicaciones de reconocimiento (y de redistribución)", pueden servir para proponer una política feminista de reconocimiento no identitaria y, más precisamente, nos permiten resolver conflictos enredados entre las reivindicaciones de reconocimiento planteadas en un eje de subordinación -cultural-religioso- y aquellas otras reivindicaciones planteadas en otro eje - género ${ }^{54}-$.

\section{LA REIVINDICACIÓN DEL DIÁLOGO: HACIA UNA RECONFIGURACIÓN EMANCIPATORIA E INTERCULTURAL DE LOS DERECHOS HUMANOS}

Por otra parte -retomando una perspectiva más abstracta y en lo que nos interesa para este trabajo-, conviene ahora recordar que de ninguna forma estamos sosteniendo participar de la lógica de la inconmensurabilidad que no nos permitiría ni valorar ni actuar. Así, reivindicar la necesidad de un paradigma de justicia social que integre junto a la distribución el reconocimiento, no significa caer en ciertas trampas de las políticas de identidad y que no tengamos presente la necesidad de convenciones jurídico-políticas que establezcan

la prohibición en escuelas, colegios y liceos públicos del "uso de signos y vestimentas mediante los cuales los alumnos manifiesten ostensiblemente una pertenencia religiosa".

53 Véase, N. FRASER, “La justicia social en la era de la política de la identidad: redistribución, reconocimiento y participación", cit., pp. 46-47. En este mismo trabajo de Fraser encontramos continuidad a lo anterior con otra referencia al tema del "asunto del velo" donde plantea que a largo plazo, y dependiendo del contexto, cabría entender que el reconocimiento puede tener efectos transformadores, como el de "reinterpretar la identidad nacional francesa para adaptarla a una sociedad multicultural, reformando el islam para un régimen pluralista liberal e igualitario respecto al género o, en general, reduciendo la relevancia política de la religión haciendo que esas diferencias sean rutinarias y triviales"; Ibidem, p. 79.

54 N. FRASER, "La política feminista en la era del reconocimiento. Un enfoque bidimensional para la justicia de género", cit., pp. 336-339. 
qué es lícito y qué no lo es; que nos indiquen qué es debido hacer en defensa de los derechos y libertades y en la corrección de las situaciones de desigualdad, discriminación y subordinación. Lo que estamos diciendo es que de la misma forma que no es posible pensar en la suficiencia de concepciones individuales y particulares, tampoco podemos caer atrapados en falsos universalismos; por lo que estas convenciones no pueden ser cerradas, ni deben ser impuestas al modo de una verdad única, universal e inmutable desde una determinada cultura hegemónica. Siguen siendo necesarias esas convenciones, esas pautas sobre cómo actuar, aunque, eso sí, resulta clave que estas estén fijadas sobre una discusión continuada en torno a la concepción compartida de lo bueno que nos pueda permitir superar la contraposición universalismo-pluralismo, igualdad y diferencia ${ }^{55}$ : que nos abra la puerta hacia "la reivindicación de unos vínculos que liberan" y donde los bienes relacionales y los comunes se definen como premisas básicas para la vida "buena" 56 ; sin por ello renunciar a reconocer sentido y valor a la diferencia y a la alteridad ${ }^{57}$.

Esta posición dialógica por la que nos decantamos, cuando menos, debería servirnos para marcar distancias con otras posiciones que no son extrañas a ser calificadas de arrogantes y triunfalistas y en las que el derecho y las políticas públicas resultan, de algún modo, cautivos de la concepción occidental del mundo. Posiciones que tienen que ver con concebir "la idea de dignidad humana transmitida por los derechos humanos como un producto singular de la historia y de la cultura occidentales que debe universalizarse como bien humano incondicional" ${ }^{58}$. Posiciones que, en cierta medida, y con

55 En realidad, con lo arriba expuesto se intenta defender la implicación mutua -y necesaria- entre la universalidad de la humanidad y el pluralismo de las formas de vida humana y, en este sentido, siguen resultando de interés las reflexiones que encontramos en $\mathrm{Z}$. BAUMAN, Comunidad, cit., pp. 147-168; y también, sobre la universalidad de los derechos fundamentales como principal garantía de las diferencias culturales reivindicadas por el multiculturalismo L. FERRAJOLI, Manifiesto por la igualdad, trad. P. Andrés Ibáñez, Trotta, Madrid, 2019, pp. 41-67.

56 Véase Ma . E. RODRÍGUEZ PALOP, “Reformular los derechos humanos desde una visión relacional. El fin de la inmunidad y la autosuficiencia", Derechos y Libertades, núm. 36, 2017, sobre todo, pp. 145-158.

57 Resultan sugerentes las provocadoras reivindicaciones de una universalidad que vaya más allá de "la simpatía y la comprensión, más allá del nivel de 'todos somos humanos'" que leemos en S. ZIZEK, La nueva lucha de clases Los refugiados y el terror, trad. D. Alou, Anagrama, Barcelona, 2016, pp. 84-95.

58 B. DE SOUSA SANTOS y B. SENA MARTINS, “Introducción”, trad. Á. Tarradellas, en B. DE SOUSA SANTOS y B. SENA MARTINS (eds.), El pluriverso de los derechos humanos. La diversidad de las luchas por la dignidad, cit., p. 10. 
el argumento de una pretendida universalidad, han cristalizado-fosilizado los derechos humanos y, a la vez, han puesto de manifiesto los límites e insuficiencias de estos para servir a su función esencial de emancipación de todas las personas en las sociedades plurales, las cuales no se encuentran exentas de tensiones marcadas por las diferentes dialécticas de globalización, por la fragmentación cultural y por las políticas de identidad. Como alternativa, Boaventura de Sousa Santos ha venido proponiendo una razón cosmopolita contrahegemónica en la que reinventar y resignificar los derechos humanos formando parte de una ecología de saberes articulada como una "sociología de las ausencias" y como una "sociología de las emergencias", acompañadas de un necesario ejercicio de traducción intercultural que nos lleva más allá de la lectura convencional que se impone sobre los derechos humanos desde Occidente y hacia una reconfiguración emancipatoria de los mismos ${ }^{59}$.

Como acabamos de apuntar, no se trata de renunciar ni al reconocimiento de la alteridad ni a la existencia de valores compartidos sin los cuales sería muy difícil, por no decir imposible, hablar de sociedades democráticas. Alertados del peligro que supone la existencia y extensión de fundamentalismos excluyentes, nos debería ocupar el ser capaces de asumir la responsabilidad de avanzar conjuntamente en la superación de esencialismos de cierre identitario y cultural que solo ven al otro, bien desde la negación y la dominación uniformizadora, o bien desde la absolutización de las diferencias. Se trata de que por medio del diálogo seamos capaces de alcanzar o acercarnos, tal vez, a una universalidad a la que Jahanbegloo se refiere como "blanda" y de la que dice que "no nos hace pensar igual, sino ser responsables ante los otros y ante nuestros problemas comunes; y nos ayuda a entrar y salir de nuestro sistema de valores relativos"; permitiendo un alto grado de diversidad cultural, de significados particulares, pero posibilitando, al

59 Sobre estas cuestiones que tienen como eje la defensa de una concepción intercultural de los derechos humanos, véanse, entre otros del mismo autor: B. DE SOUSA SANTOS, "Las tensiones de la modernidad", trad. Ma . del Mar Portillo y M. Barberi, en M. MONEREO y M. RIERA (eds.), Porto Alegre. Otro mundo es posible, El viejo topo, Barcelona, 2001, pp. 163-189; Id., El milenio huérfano. Ensayos para una nueva cultura política, trad. Joaquín Herrera y otros, Trotta, Madrid, 2005, pp. 151-192; e Id., Sociología jurídica crítica. Para un nuevo sentido común en el derecho, trad. Carlos Lema y otros, Trotta-ILSA, Madrid-Bogotá, 2009, pp. 509-541 (de este capítulo, "Hacia una concepción intercultural de los derechos humanos", también está la versión: Id., "Towards a multicultural conception of Human Rights", en F. GÓMEZ ISA and K. DE FEYTER (eds.), International Human Rights Law in a Global Context, University of Deusto, Bilbao, 2009, pp. 97-121). 
mismo tiempo, el universal mínimo compartido necesario en la garantía de toda convivencia ${ }^{60}$.

En realidad, con esta propuesta de tratamiento jurídico-político a desarrollar en las sociedades plurales no estamos haciendo otra cosa que apostar por la "cultura del diálogo" como base necesaria para dejar a un lado las asimetrías que generan violencia, desigualdad y discriminación y, simultáneamente, acercarnos al "descubrimiento del otro" en su diferencia y en el significado de su alteridad ${ }^{61}$. Un diálogo, así, que actúe como conversación abierta y compartida que atraviese -y desestabilice- los sistemas de opresión y dominación; un diálogo donde reconciliar la igualdad con el pluralismo y la diferencia, que no con la desigualdad, de tal forma que permita la cohabitación de la diversidad con la capacidad inclusiva de los derechos humanos; un diálogo que habilite espacios y tiempos donde desarrollar una voluntad de convivencia que genere vínculos y relaciones, que promueva percepciones compartidas de las cosas, que permita, en fin, y dentro de esta apología del diálogo, la realización de la persona como ser moral en su comunicación con los otros ${ }^{62}$.

60 Véase R. JAHANBEGLOO, Elogio de la diversidad, trad. J. G. López Guix, Arcadia, Barcelona, 2007, pp. 39-48, donde se defiende la apuesta por esta universalidad "blanda", alejada tanto de relativismos políticos y morales absolutos como de tentaciones de uniformización, homogeneización y uniformidad cultural, y que, por contra, posibilita un alto grado de diversidad cultural, de encuentro y de diálogo democrático.

61 En J. I. MARTÍNEZ GARCÍA, "Cuestión migratoria y descubrimiento del otro", Derechos y Libertades, núm. 39, 2018, pp. 63-95, encontramos, a partir de la "cuestión migratoria", un sugerente recorrido por distintos autores (Husserl, Gadamer, Ortega y Gasset, Luhmann, Levinas...) hasta llegar a la reivindicación de las oportunidades que se abren con el "descubrimiento del otro". También aquí resultan de interés las reflexiones que realiza $\mathrm{O}$. PÉREZ DE LA FUENTE, "Un análisis sobre la Regla de Oro como un enfoque intercultural para la resolución de conflictos", Universitas, núm. 26, 2017, pp. 68-98.

62 Véase J. J. TAMAYO, “Apología del diálogo ante los fundamentalismos”, en B. DE SOUSA SANTOS y B. SENA MARTINS (eds.), El pluriverso de los derechos humanos, cit., pp. 109-129, donde, tras un análisis crítico de los fundamentalismos (y no solo religiosos), se plantean las razones para una "apología del diálogo", al que se defiende como "forma de vida, talante, imperativo ético". En una línea similar, R. JAHANBEGLOO, Elogio de la diversidad, cit., pp. 18 y 23, donde leemos: "El futuro de nuestra civilización global en este frágil y vulnerable planeta depende de nuestra capacidad para vivir juntos -con nuestras diversidades-, si no en armonía, sí al menos con capacidad para el diálogo y el entendimiento mutuo. (...) El diálogo intercultural es el medio esencial para promover una percepción compartida de las cosas y de los acontecimientos". Igualmente de interés es la reivindicación de la "cultura del diálogo" que realizó el papa Francisco al recibir el Premio Carlomagno (versión en castellano en: http://w2.vatican.va, en sección discursos-mayo 2016; última consulta en diciembre 2019); y sobre cómo puede servir esta reivindicación a una integración cosmopolita sin separación

DERECHOS Y LIBERTADES

ISSN: 1133-0937

Número 44, Época II, enero 2021, pp. 41-79

DOI: https://doi.org/10.20318/dyl.2021.5849 
Pero, además, creo que podemos sostener que esta reivindicación del diálogo no es una mera cuestión retórica -un "juego floral" básico frente a la aridez de lo jurídico-. Desde el diálogo cabe avanzar, por ejemplo, en nuevos derechos emergentes a la manera del que se ha definido como derecho a la democracia plural $^{63}$. Y, sobre todo, desde el diálogo y de alguna manera retomando la idea de dignidad citada -pero también el reconocimiento de todas las personas en su plena humanidad, con lo que ello conlleva de poder representar el mundo como propio y, así, pasar de objeto de discursos a sujeto de derechos-, conviene proponer una revisión de los derechos humanos con el objetivo de recuperar su potencial emancipador. Lo que exige diluir las líneas y fronteras que de Sousa Santos identifica en el pensamiento moderno occidental como "pensamiento abismal", que divide y excluye, y que lleva a negar cualquier narrativa no convencional de la dignidad, a considerarla como un no existente, ininteligible y peligroso ${ }^{64}$. Desde estos planteamientos, deberíamos ser capaces de acercarnos a miradas que, siguiendo con de Sousa Santos, subviertan la comprensión occidental, liberal e individualista del mundo, facilitando una concepción contrahegemónica de los derechos humanos y contribuyendo a reinventar las gramáticas de la dignidad. Y es aquí donde encajaría la propuesta de un constante ejercicio de traducción intercultural: un continuo y necesario trabajo de traducción, de inteligibilidad recíproca entre saberes, culturas y experiencias diversas que recupere las posibilidades emancipatorias de los derechos a través de su reinvención intercultural; algo para lo que se requiere no solo de cuestiones teóricas abstractas que, por otra parte, llevan el riesgo de alejarnos de cualquier posibili-

"nosotros-ellos", Z. BAUMAN, Retrotopía, trad. A. Santos Mosquera, Paidós, Barcelona, 2017, pp. 149-161.

63 El derecho a la democracia plural ("Todos los seres humanos y toda comunidad tienen derecho al respeto de la identidad individual y colectiva, así como el derecho a la diversidad cultural") viene recogido en el artículo 5 de la Declaración Universal de Derechos Humanos Emergentes como derecho que comprende los siguientes: el derecho a la interculturalidad; el derecho individual a la libertad cultural; el derecho al reconocimiento y protección de la identidad cultural común; el derecho al honor y la propia imagen de los grupos humanos; el derecho de los pueblos indígenas, los afrodescendientes, las minorías y las personas que los integran a medidas especiales de reconocimiento de sus peculiaridades; o, entre otros, el derecho a la libertad de conciencia y religión (se puede acceder a esta Declaración a través de: www.idhc.org/arxius/recerca/1416309302-DUDHE.pdf; última consulta en diciembre de 2019).

64 Sobre este "pensamiento abismal" o "abisal", véase B. DE SOUSA SANTOS, Para descolonizar Occidente. Más allá del pensamiento abismal, Consejo Latinoamericano de Ciencias Sociales (CLACSO) - Prometeo Libros, Buenos Aires, 2010, pp. 11-44. 
dad contrahegemónica, sino que también necesita de las luchas y resistencias que reinventan efectivamente las gramáticas de la dignidad ${ }^{65}$.

Este trabajo de traducción incidiría tanto en saberes y culturas -la hermenéutica diatópica- como sobre prácticas sociales, sus agentes y experiencias, y nos permitiría dar sentido a un mundo plural, diverso y complejo en el que conviene que las posiciones -incluidas las que se tienen sobre la dignidad y los derechos humanos- que se pretenden hegemónicas y excluyentes dejen paso al diálogo y reconocimiento mutuo ${ }^{66}$. Y, sobre todo, este trabajo de traducción y diálogo nos permitiría asumir una visión compleja en torno a la racionalidad y la práctica de los derechos humanos, de tal manera que se superen las perspectivas unidimensionales que nos pueden aportar aisladamente visiones abstractas (con una racionalidad jurídico-formal y prácticas universalistas), de un lado, y visiones localistas (con una racionalidad material-cultural y prácticas particularistas), de otro; desplegándose como una visión que responda al esquema de racionalidad de resistencia y práctica intercultural, abandonando un modelo etnocéntrico, cerrado y excluyente y avanzando hacia una propuesta de cultura de los derechos que "recoja en su seno la universalidad de las garantías y el respeto por lo diferente". Es decir, con la traducción y el diálogo que habilitan a esta mirada compleja se nos

65 En este sentido, en B. DE SOUSA SANTOS y B. SENA MARTINS (eds.), El pluriverso de los derechos humanos, cit., encontramos la recopilación de una serie de trabajos de distintos autores resultado del intercambio y diálogo en el marco del proyecto ALICE, y a través de los cuales, como se recoge en la "Introducción”, "comparece un pluriverso de lenguajes, geografías y cuerpos en lucha" (p. 21) desde donde pensar el valor emancipador de los derechos humanos; especialmente vinculados con lo arriba recogido están los capítulos que conforman la segunda parte del libro: "Luchas y emergencias", pp. 145-534.

66 En B. DE SOUSA SANTOS, El milenio huérfano. Ensayos para una nueva cultura política, cit., pp. 151-192, se definen las condiciones y procedimientos del ejercicio de traducción que ha de servir para crear unas condiciones de emancipación concretas y, desde la reinvención de un presente que se expande -frente a un futuro que se contrae-, derivar en prácticas transformadoras en las que los derechos humanos se reconceptualicen como parte de un proyecto cosmopolita insurgente. Mientras que en Id., Sociología jurídica crítica. Para un nuevo sentido común en el derecho, cit., pp. 527-533, se recoge la advertencia de que en la realización de dicho trabajo de traducción, la hermenéutica diatópica, clave para el intercambio intercultural, no tiene garantizado a priori un carácter emancipador " $y$, de hecho, el multiculturalismo puede convertirse en el nuevo rótulo de una política reaccionaria"; desde donde de Sousa Santos plantea "las condiciones para una reconstrucción intercultural de derechos humanos", entre otras: no establecer unilateralmente para el diálogo ni tiempos ni socios ni temas y aceptar el imperativo transcultural de que "tenemos el derecho de ser iguales cuando la diferencia nos inferioriza y el derecho de ser diferentes cuando la igualdad pone en peligro nuestra identidad", cuando nos descaracteriza. 
deberían abrir las alternativas hacia posiciones periféricas que nos permitan "entendernos como manojos de relaciones que nos atan, tanto interna como externamente, a todo lo demás y a todos los demás", que nos lleven a aprender del contexto plural y diverso y que nos conduzcan a asumir la realidad desde la perspectiva democrática de que todas las voces cuentan ${ }^{67}$.

\section{LA PERSPECTIVA INTERSECCIONAL}

Siempre con el objetivo de una concepción integradora de la justicia, esta revisión de los derechos humanos -y con ella la recuperación del significado pleno de estos en su potencial emancipador, en su valor contrahegemónico y en su capacidad para avanzar hacia ese derecho emergente reconocido como derecho a la democracia plural- requiere de nuevas herramientas con las que, como decíamos: la persona pase de ser considerada objeto de discursos a ser reconocida como sujeto de derechos. Y entre estas nuevas herramientas de análisis merece la pena fijarnos unas líneas en la que se nos propone como interseccionalidad. Más en concreto, se trataría ahora de recurrir a la perspectiva que aporta la interseccionalidad para poder avanzar en una idea revisada de la igualdad desde la que superar la ya citada concepción estándar a través del reconocimiento de la relevancia de su facticidad. Esto es, atendiendo al déficit que, en ocasiones, una realización justa de la igualdad presenta si se condiciona únicamente al cumplimiento de criterios universales y abstractos $^{68}$.

Volviendo al caso del velo y a las propuestas de actuación jurídico-política sobre el mismo, como nos alerta Leila Slimani: “No existe el velo. Hay mil maneras de llevar velo y significados extremadamente diferentes. Una mujer con velo no es solo eso, tiene una historia, sus razones. $Y$ parece que no se vea más que el velo" ${ }^{69}$. Y es por esta complejidad por lo que se muestra

67 J. HERRERA, "Hacia una visión compleja de los derechos humanos", en Id. (ed.), El vuelo de Anteo. Derechos humanos y crítica de la razón liberal, Desclée de Brouwer, Bilbao, 2000, pp. 19-78, donde se propone una visión compleja de los derechos humanos de la que debería surgir una racionalidad de resistencia crítica que nos conduzca "a un universalismo de contrastes, de entrecruzamientos, de mezclas" y a una práctica social intercultural (ni universalista ni multicultural), nómada e híbrida.

68 Es lo que se viene a plantear en L. VILLAVICENCIO MIRANDA, "Justicia social y el principio de igualdad", cit., pp. 67 y ss. cuando se proponen como nuevos elementos para una concepción revisada de la igualdad el particularismo y la interseccionalidad.

69 El País de 31 de octubre de 2019.

ISSN: 1133-0937

DOI: https://doi.org/10.20318/dyl.2021.5849
DERECHOS Y LIBERTADES

Número 44, Época II, enero 2021, pp. 41-79 
oportuno incorporar elementos que nos ayuden a conocer esas situaciones y a evitar el déficit al que nos referíamos en el párrafo anterior, que puede derivar, con un tratamiento jurídico-político insensible a la diversidad -y a lo enredado de esta-, en situaciones de desigualdad y subordinación. En este sentido, nos puede resultar de utilidad el concepto de interseccionalidad que reivindica Kimberlé Crenshaw con un trabajo de finales de la década de los ochenta del siglo pasado y a través del cual se viene a plantear, para comprender la forma particular en que las mujeres negras están subordinadas, que no sirve con atender a la experiencia de las mujeres y a la experiencia negra ni sirve quedarse en una suma de sexismo y racismo, sino que se trata de atender a una situación de interseccionalidad, de entrecruzamiento de múltiples pertenencias que llevan a particulares situaciones de opresión o privilegio $^{70}$.

De esta forma, "la perspectiva interseccional es una herramienta conceptual y política capaz de visibilizar y analizar la desigualdad compleja en nuestras sociedades", que nos muestra los límites de las prácticas políticas y jurídicas que fragmentan esta realidad y se olvidan de las interacciones en torno a las desigualdades y a los sistemas y estructuras (género, raza, clase...) que las producen ${ }^{71}$. Igualmente, nos puede servir para hacer frente a

70 K. CRENSHAW, "Demarginalizing the Intersection of Race and Sex: A Black Feminist Critique of Antidiscrimination Doctrine, Feminist Theory and Antiracist Politics", University of Chicago Legal Forum, vol. 1989: núm. 1, article 8, 1989, pp. 139-167 (la referencia utilizada aquí es la accessible on line, última consulta noviembre 2019: https://chicagounbound. uchicago.edu/uclf/vol1989/iss1/8/). Véase también, Ma. Á., BARRÈRE, “La interseccionalidad como desafío al mainstreaming de género en las políticas públicas”, cit., pp. 228 y ss., donde encontramos una útil aproximación al origen y proyección de la interseccionalidad desde una perspectiva feminista, así como a lo que puede suponer para las políticas de igualdad de género, y donde se concluye que si bien su incorporación puede tener elementos de reconocimiento positivos y antidiscriminatorios, también se alerta de que su toma en consideración no puede conllevar la disolución del "factor sexo-género como eje principal en las políticas públicas (no solo de igualdad)"; y refiriéndose al tema de la prohibición del velo y defendiendo la utilidad de la interseccionalidad si con ella se atiende a las interacciones de los sistema de opresión: D. MORONDO, "Between Islamophobia and post-feminist agency: intersectional trouble in European face veil bans", Feminist Review, núm.110, 2015, pp. 55-67.

71 M. CRUELLS LÓPEZ, La interseccionalidad política: tipos y factores de entrada en la agenda política, jurídica y de los movimientos sociales, 2015, tesis doctoral accesible on line, última consulta noviembre 2019, en: https://ddd.uab.cat/pub/tesis/2015/hdl_10803_288224/mcl1de1.pdf; en ella se analiza, a partir de un recorrido por la teoría de la interseccionalidad y a través del estudio de casos, la incorporación de la perspectiva interseccional en las políticas públicas, movimientos sociales y práctica jurídica.

DERECHOS Y LIBERTADES

ISSN: 1133-0937

Número 44, Época II, enero 2021, pp. 41-79

DOI: https://doi.org/10.20318/dyl.2021.5849 
los riesgos de reificación de aquellas políticas de reconocimiento que, en su defensa absoluta de la identidad, acaben imponiendo la identidad del grupo y negando la complejidad de las vidas de las personas y la multiplicidad de sus identificaciones, como vimos que denunciaba Fraser ${ }^{72}$. Y es en relación con esto que la incorporación de la interseccionalidad se muestra como una alternativa útil tanto para superar los intentos de determinados subgrupos de universalizar sus experiencias como para tener en cuenta la no existencia de un todo homogéneo como, asimismo, para considerar las diferencias intragrupales moldeadas por distintos entrecruzamientos que las políticas de identidad tienden a invisibilizar ${ }^{73}$. Como recoge Barrère, la incorporación de la interseccionalidad significa: "Reconocer que las políticas públicas de igualdad no pueden ignorar que las mujeres no configuran un grupo homogéneo (que tienen distinta orientación sexual, etnia, clase, religión, etc.) ni que, históricamente, un determinado subgrupo de mujeres (blancas, de clase media-alta, occidentales, etc.) ha universalizado sus experiencias, intereses y necesidades en detrimento de los de muchos otros. Tampoco puede pasar por alto que, en ocasiones, los intereses de los subgrupos de mujeres, dependiendo de los factores mencionados, pueden diferir" 74 .

72 "Las luchas de hoy por el reconocimiento a menudo adoptan el talante de la política de identidad. (...) Los resultados tienden a ser doblemente desafortunados: en muchos casos, (...) desplazan simultáneamente las luchas por la justicia económica y promueven formas represivas de comunitarismo. (...) Lo que hace falta, más bien, es una política de reconocimiento alternativa, una política no identitaria que sea capaz de remediar el mal reconocimiento sin alentar el desplazamiento y la reificación”; N. FRASER, “Repensar el reconocimiento. Superar el desplazamiento y la reificación en la política cultural”, cit., pp. 323-324. Pues bien, si para esa política alternativa de reconocimiento, de un lado, en lo que se refiere al desplazamiento de las luchas por la justicia económica, se ha de integrar reconocimiento con redistribución; de otro lado, cabe pensar en la aportación de la perspectiva interseccional para evitar la tendencia a reificar las identidades colectivas y, así, reconocer a cada persona en la interacción de sus diferencias.

73 "Como tal, la diversidad constituye un fenómeno intrínsecamente formado por distintas condiciones que la moldean conjuntamente de una manera que no puede ser definida a priori, poniendo de relieve su origen complejo y su interconexión originaria con diferentes condiciones de identificación y discriminación social como el género, la 'raza' / etnia y la clase social, entre otras", S. GARCÍA-PETER y L. VILLAVICENCIO, "Alcances y límites del multiculturalismo liberal desde un enfoque de género interseccional", Convergencia. Revista de Ciencias Sociales, núm. 72, 2016, pp. 15-18.

${ }_{74} \mathrm{M}^{\mathrm{a}}$. Á. BARRÈRE, “La interseccionalidad como desafío al mainstreaming de género en las políticas públicas”, cit., p. 251. 
Esto es, y quizás como algo no exento de una cierta paradoja, a la vez que la perspectiva interseccional puede ser pensada como una vía para aportar luz sobre el poder, sobre cómo se distribuyen y redistribuyen los privilegios y sobre cómo se despliegan los procesos de opresión, dominación y subordinación en contextos y momentos concretos, también puede servirnos para visibilizar y aportar algo de luz sobre la complejidad de las diferencias que caracterizan a cada persona, algo que se tiende a ocultar, en ocasiones, en la clausura de las identidades colectivas. Además, en relación con esto, frente a los riesgos de desubjetivización ya indicados al hilo del comentario de la norma francesa sobre el velo integral y la resolución del TEDH de julio del 2014, la perspectiva interseccional nos puede servir para estar más atentos a las trayectorias biográficas de las personas, a fin de atenuar los condicionantes particulares que dificulten su autónomo desarrollo individual y social.

Y aquí, finalmente, nos aparece otra paradoja que exige una mayor atención para no echar por tierra el potencial emancipador de la perspectiva interseccional. Pues si bien es cierto que una puesta en práctica de esta perspectiva, con la conveniente acción política y legislativa antidiscriminatoria ${ }^{75}$, podría alcanzar a corregir la tendencia a la desubjetivización y, desde allí, avanzar hacia el empoderamiento de las personas; es igual de cierto que existe el riesgo de acabar participando de una corriente que tiende a individualizar los problemas sociales, su percepción, análisis y tratamiento a través del derecho y la política. Paradoja que, tal vez, se pueda resolver acudiendo al múltiple significado que podemos darle al concepto de empoderamiento, por el que no solo es posible entender la capacidad de elegir y de actuar de manera efectiva conforme a las elecciones realizadas, la capacidad de tener cierto control sobre nuestra trayectoria vital. Al hablar de empoderamiento también podemos estar refiriéndonos a un concepto que no deja de ser parte de la estrategia individualizadora neoliberal que hace de los individuos los únicos responsables de su propio devenir, de sus éxitos y de sus fracasos, de las explotaciones, dominaciones y desigualdades en las que habitan. La desigualdad, la pobreza, el patriarcado... no tienen solución, pero usted, si no

75 Sobre el alcance y aportación del derecho antidiscriminatorio en la determinación de las estructuras de discriminación y en la identificación de los grupos desaventajados, frente a los modelos dominantes que tienen los sistemas jurídicos de pensar la discriminación, y en lo que se refiere a la incorporación del enfoque de la discriminación estructural y de la perspectiva interseccional, véase $\mathrm{M}^{\mathrm{a}}$. J. AÑ́n, "Principio antidiscriminatorio y determinación de la desventaja", Isonomía, núm. 39, octubre-2013, pp. 127-157. 
se distrae, si centra sus objetivos, sí puede mejorar. Es un empoderamiento que muerde sin fuerza las injusticias y desigualdades de la estructura de las relaciones sociales, que no participa de ningún proceso de emancipación, que no se plantea cuestiones de justicia social; que se ocupa únicamente de facilitar que cada uno desarrolle sus capacidades individuales, que sea capaz de realizar elecciones racionales, útiles y efectivas y tenga un nivel de oportunidades suficientes para encontrar su lugar en la economía de mercado, para ser "gestor de su propia vida" -de la que es el único responsable, de éxitos y fracasos-, para ser un homo economicus que contribuya a reproducir y a hacer funcional el sistema ${ }^{76}$.

Por el contrario, si queremos seguir pensando en la interseccionalidad como una perspectiva útil para una concepción integradora de la justicia; para no caer en las trampas de desplazamiento y reificación; para posibilitar una revisión de los derechos que recupere su capacidad emancipadora y sirva para avanzar hacia la democracia plural, probablemente la cuestión pase por pensar otro empoderamiento. Un empoderamiento que marque distancias con el anterior en su (in)-capacidad de cuestionamiento de la realidad; que tenga en cuenta no solo los efectos, también las causas y estructuras de dominación, discriminación y desigualdad; que sea reflejo del valor crítico y no complaciente del pensamiento; que en el plano de los derechos sea consciente de que la mera titularidad de estos puede generar expectativas engañosas, a modo de luz de gas... Un empoderamiento, finalmente, que requiera del diálogo, de la participación intensa y del compromiso con lo común y, para ello, de la generación de las relaciones como elemento clave para una implicación mutua entre las personas que habitamos una misma sociedad.

Y en relación con estas últimas cuestiones apuntadas, y para acabar, creo que puede resultar sugerente mencionar el proyecto de Pierre Rosanvallon Explicar la vida y su "Parlamento de los invisibles" como una forma de facilitar nuevas oportunidades de empoderamiento, de visibilización democrática del individualismo de singularidad y de reconocimiento social. Se trata de un proyecto donde la palabra y la escucha son productoras de comunidad y relación social; cuyo motor es aceptar que en una sociedad diversa, donde

76 Sobre este "secuestro" del empoderamiento por el neoliberalismo y, también, por el liberalismo social, perdiendo toda su potencialidad de transformación social, véase M-H. BACQUÉ y C. BIEWENER, El empoderamiento. Una acción progresiva que ha revolucionado la política y la sociedad, trad. S. Nora Labado, Gedisa, Barcelona, 2016, sobre todo, pp. 69-106. 
todo cambia y se mueve al instante, donde la complejidad es la regla y no caben lecturas unidimensionales, la información y el conocimiento sobre los demás tienen la función de reducir distancias entre las personas, con lo que se trasciende lo social y lo político y se alcanza una dimensión moral, en el sentido de contribuir a desarrollar el interés por los demás. Un proyecto -concluye Rosanvallon- que, de un lado, nos ha de servir para evitar retrocesos y cierres identitarios vinculados con el crecimiento de los populismos y racismos que pudren la politica elevando a real "la figura abstracta de un pueblo único y homogéneo"; mientras que, de otro, "a rebufo de una visión tan negativa del vínculo social que opera solo mediante la sustracción y el rechazo, (...) proveerá, sin duda, los elementos de una reconstrucción positiva de un mundo común, reconocido en su diversidad y en su realidad" 77 .

\section{A MODO DE BREVE CONCLUSIÓN}

La realidad de las desigualdades complejas y entrelazadas propias de nuestras sociedades plurales conforma un círculo vicioso de subordinación. Así, siendo necesario actuar en los ámbitos de la desigualdad vital y de recursos, también se exige actuar en el de la desigualdad existencial, la cual, a su vez, requiere pensar tratamientos jurídico-políticos que, por supuesto, eviten el populismo punitivo y las iniciativas prohibicionistas y sancionadoras; pero también posibles efectos perversos (estigmatización, riesgo de desubjetivización, cierre identitario, reificación de las identidades, refuerzo de situaciones de subordinación y discriminación...). En este sentido, una propuesta de actuación nos lleva a Fraser y a su concepción de la justicia que integra reconocimiento y redistribución, y centra nuestro interés, para el caso que nos ha ocupado (el velo islámico, en especial, el velo integral), en el modelo de estatus de reconocimiento y en la noción de paridad de participación, a lo que tenemos que añadir las posibilidades que para la detección y superación de situaciones de discriminación ofrece la perspectiva interseccional. Finalmente, en la complejidad de las sociedades actuales, la realización de una idea de justicia que integre reconocimiento-redistribución (y representación) exige dejar a un lado posiciones etnocéntricas y abrirse

77 P. ROSANVALLON, El Parlamento de los invisibles, trad. R. Fernández, ed. HacerServicio de publicaciones de la Fundació Apip-Acam, Barcelona, 2015, pp. 19-66 (en esta edición, estas páginas son las que corresponden a la aportación de Rosanvallon y se acompañan de reflexiones de otros autores).

DERECHOS Y LIBERTADES

ISSN: $1133-0937$

Número 44, Época II, enero 2021, pp. 41-79

DOI: https://doi.org/10.20318/dyl.2021.5849 
hacia una dimensión dialógica y relacional como vía para una resignificación emancipatoria e intercultural de los derechos humanos que nos permita avanzar hacia el reconocimiento del derecho a la democracia plural como derecho emergente.

\author{
RAÚl Susín BETRÁN \\ Departamento de Derecho \\ Facultad de Ciencias Jurídicas y Sociales \\ Universidad de La Rioja \\ c/Cigüeña, 60 - 26006 Logroño \\ e-mail:raul.susin@unirioja.es
}

ISSN: 1133-0937

DOI: https://doi.org/10.20318/dyl.2021.5849
DERECHOS Y LIBERTADES

Número 44, Época II, enero 2021, pp. 41-79 